Chapter 20

\title{
The Redesign of Processes' Development in Food Production Organizations Using Quality Engineering Methods and Tools
}

\author{
Slavko Arsovski, Miladin Stefanović, \\ Danijela Tadić and Ivan Savović
}

Additional information is available at the end of the chapter

http://dx.doi.org/10.5772/53154

\section{Introduction}

A number of trends and challenges such as increased competition, new technologies and regulations, quality and new consumer trends have been forcing the food industry to change $[1,2,3]$. In response to these new challenges, food companies are improving competitiveness by restructuring, redesigning existing processes, and intensifying the fight for market share through product differentiation and/or the development of new food products [1]. In order to improve, companies in the food industry must adopt: Restructure of their organizations and redesign their processes; Automation of production and other processes to decrease dependence on human resources and transfer activities to self-service facilities for customers and partners; Optimization of logistical infrastructure and systems; Energy saving measures through new technology and materials, new production methods and goodpractice implementation; Political and regulatory developments (food safety and other regulations); Technological changes (biotechnology, ICT and RFID, robotics, sensors, e-business); Understand globalization, market developments and customer trends.

In this chapter process development is analyzed because of its impact on food quality, safety and sustainability $[4,5,6]$. A redesign of process development could be accomplished through many different approaches, techniques and tools [7, 8, 9, 10]. In this chapter Business Process Management (BPM) is used with accompanied quality engineering methods and tools. A number of important questions will be addressed concerning the redesign of process development in food production organizations using quality engineering tools and methods. 
The first question that will be raised is the quality of processes in the food industry. The analysis will start from a typical process map for companies in the food processing industry in Serbia. After that the production process, as one of the most important processes in food processing will be decomposed. For each sub process appropriate metrics will be defined as the road of evaluation for the quality of the sub processes and quality of the goal of the process itself. Redesign of process development will be analyzed by comparing different approaches and by consideration of process redesign as the process. Different quality engineering methods and tools in the food industry will be compared according to the frequency of their implementation in the Serbian food industry as well as a correlation between the application of different quality engineering methods and tools, and profit in the companies. As an extension of the general ranking idea presented on the ranking and definition of goals in the production process, a fuzzy approach for evaluation of the importance of entities in supply chains in the food industry is presented. The general idea is to present an application of a mathematical tool in a situation that is very common in the food industry where conditions have been constantly changing so the observed values could not be stochastically described and where there is not a sufficient amount of data for statistical analysis. In other words, the application of fuzzy sets on evaluation of the importance of entities in the supply chain will be presented. A strategic map as a strategic part of the BSC (Balanced Score Card) framework is presented as one of the quality engineering methods. The presented strategic map started from the Kaplan - Norton model but it was adjusted in order to meet the needs of food processing companies in Serbia. Relations between entities (from all four perspectives) are defined as the result of research among Serbian companies. In the final part of the chapter the process framework for food processing companies is presented. The questionnaire used for the research is presented as well as gathered data from 53 Serbian companies. The gathered data was the input in modeling and evaluations presented in previously discussed issues.

The main idea of the chapter is to provide an overview of the redesign of process development, starting from analysis (decomposition of processes), redesign, implementation of modern quality engineering tools and methods (frequency of usage and impact of different tools and methods and implantation of some of them) as well as theoretical and mathematical tools on ranking of quality goals (theory of fuzzy sets) and finally providing a process framework and, at the same time, the keeping a connection and solid ground in data gathered from the food industry.

\section{Quality of processes in the food industry}

The food industry contains a number of completely different processes which require a wide range of measuring instruments. On the one hand, the quality of processes has market goals in brand development, demand management and new product introduction, while embracing food security and quality requirements. On the other hand, quality of processes in the food industry depends on many factors such as customer demands, key performance indicators, the process map, technology level, management level etc. In order to provide quality 
analysis, and redesign and improvement of the process the first step is an analysis of the process map of a typical organization in the food industry. A typical process map for an organization in the food industry is presented in figure 1.

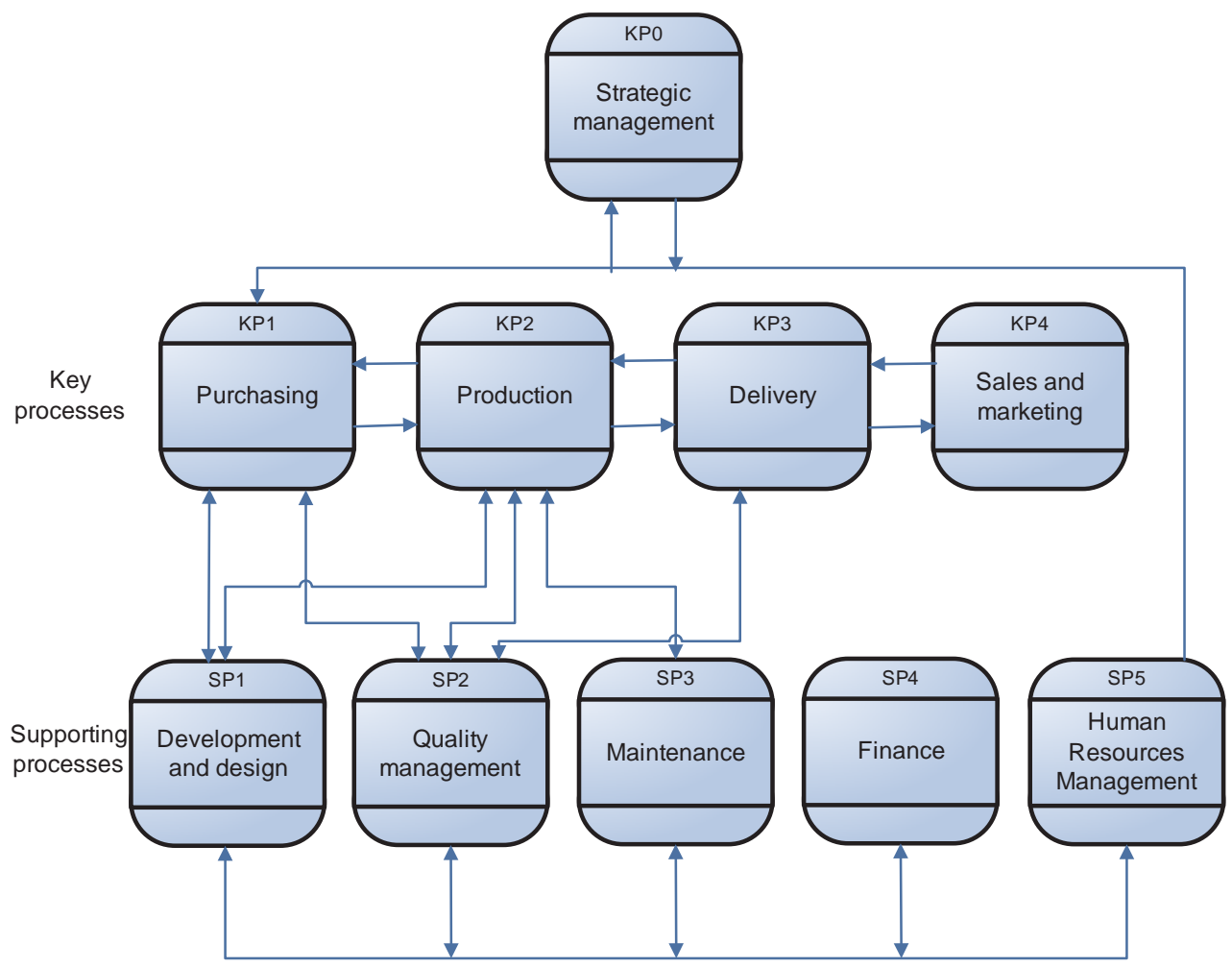

Figure 1. Typical process map for organizations in the food industry

Besides strategic management, each component process is functioning at a tactical and operative level and has quality metrics. In this chapter the major focus will be placed on the production process (KP2), all other decompositions could be performed using the same pattern, with appropriate quality metrics. In further analysis the production process could be decomposed into the sub processes presented in figure 2 .

The production process (according to figure 2) consists of four sub processes: Logistic process, Process realization, Process planning and scheduling and Production process control.

In further analysis the logistic sub process (KP 2.1) could be decomposed into the following sub processes: Definitive logistic strategy; Plan inbound material flow; Operate outbound warehousing; Operate transportation and Manage reverse logistics. 


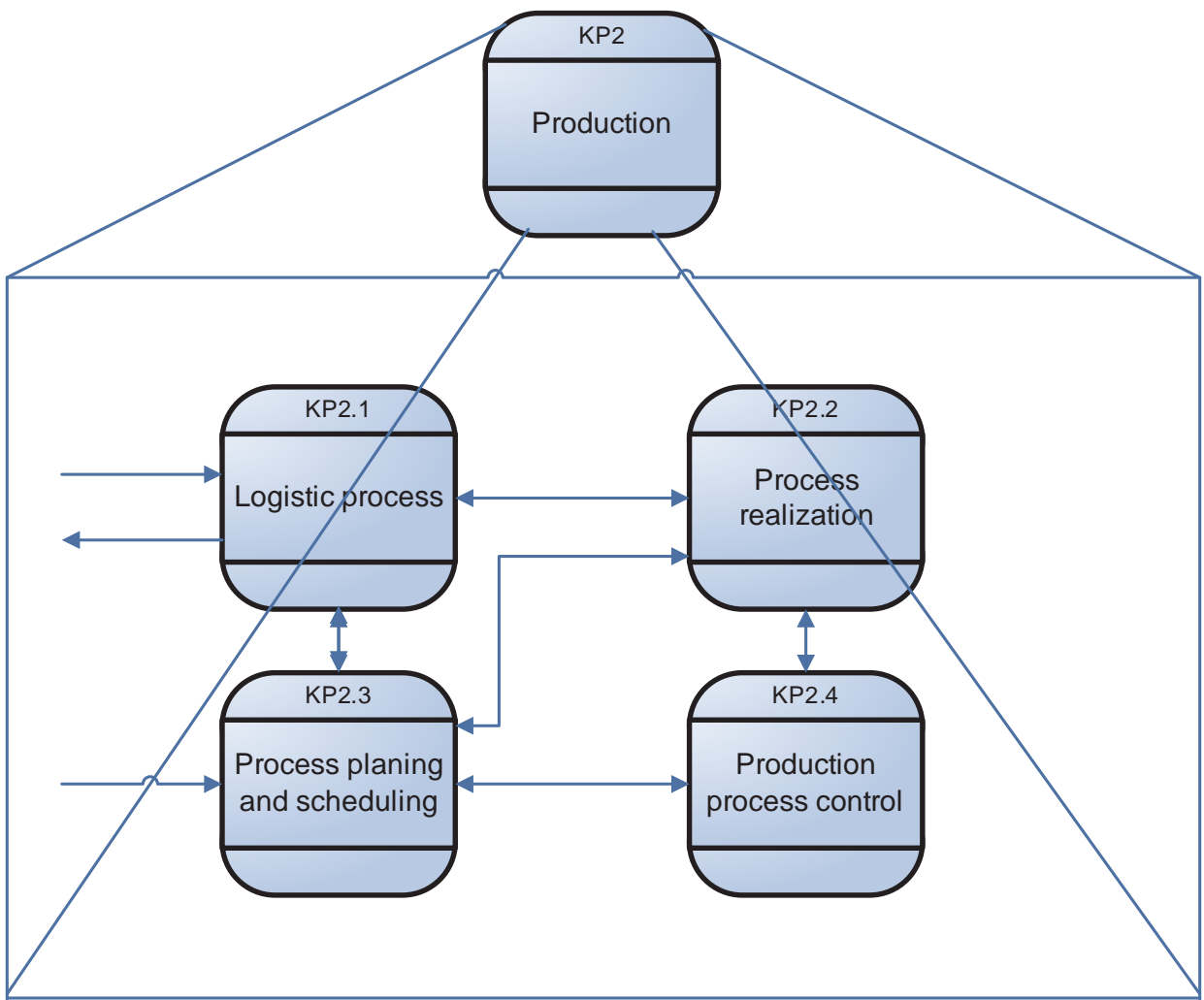

Figure 2. Decomposition of production process

The next important step is the definition of quality metrics. According to the definition a metric is a verifiable measure stated in either quantitative or qualitative terms. Quality metric data may be used to: spot trends in performance, compare alternatives and predict performance. Organizations need to collect information for a particular quality metric in order to evaluate and improve their processes. For further analysis of the logistic process the following quality metrics are presented in Table 1.

The second sub process of KP2, Production process realization (KP 2.2) is decomposed into sub processes: Preparing workers for obligatory measures; Preparing working places; Realization of working activities and Work reporting. The accompanied quality metrics are presented in table 2 .

Production process planning and scheduling (KP 2.3) is decomposed into the following sub processes: Manage demand for products; Create material requirement plan (MRP) and Schedule production. The accompanied quality metrics are presented in table 3. 


\begin{tabular}{lllll}
\hline $\begin{array}{l}\text { Logistic strategy } \\
\text { realization } \%\end{array}$ & $\begin{array}{l}\text { Realization of } \\
\text { inbound plan of } \\
\text { material flow }\end{array}$ & $\begin{array}{l}\text { Costs of } \\
\text { warehousing /plan } \\
* 100\end{array}$ & $\begin{array}{l}\text { Realization of plan } \\
\text { of outbound } \\
\text { transportation }\end{array}$ & Score \\
\hline $95-100$ & $>100$ & $<50$ & $>100$ & 10 \\
\hline $85-95$ & $90-100$ & $50-60$ & $90-100$ & 9 \\
\hline $75-85$ & $80-90$ & $60-70$ & $80-90$ & 7 \\
\hline $65-75$ & $70-80$ & $70-80$ & $70-80$ & 6 \\
\hline $55-65$ & $60-70$ & $80-90$ & $60-70$ & 5 \\
\hline $45-55$ & $50-60$ & $90-100$ & $50-60$ & 4 \\
\hline $35-45$ & $40-50$ & $100-110$ & $40-50$ & 3 \\
\hline $25-35$ & $30-40$ & $110-120$ & $30-40$ & 2 \\
\hline$<25$ & $<30$ & $>120$ & $<30$ & weight \\
\hline 0.25 & 0.25 & 0.25 & 0.25 & 85 \\
\hline
\end{tabular}

Table 1. Quality metrics of "Logistic process" KP 2.1

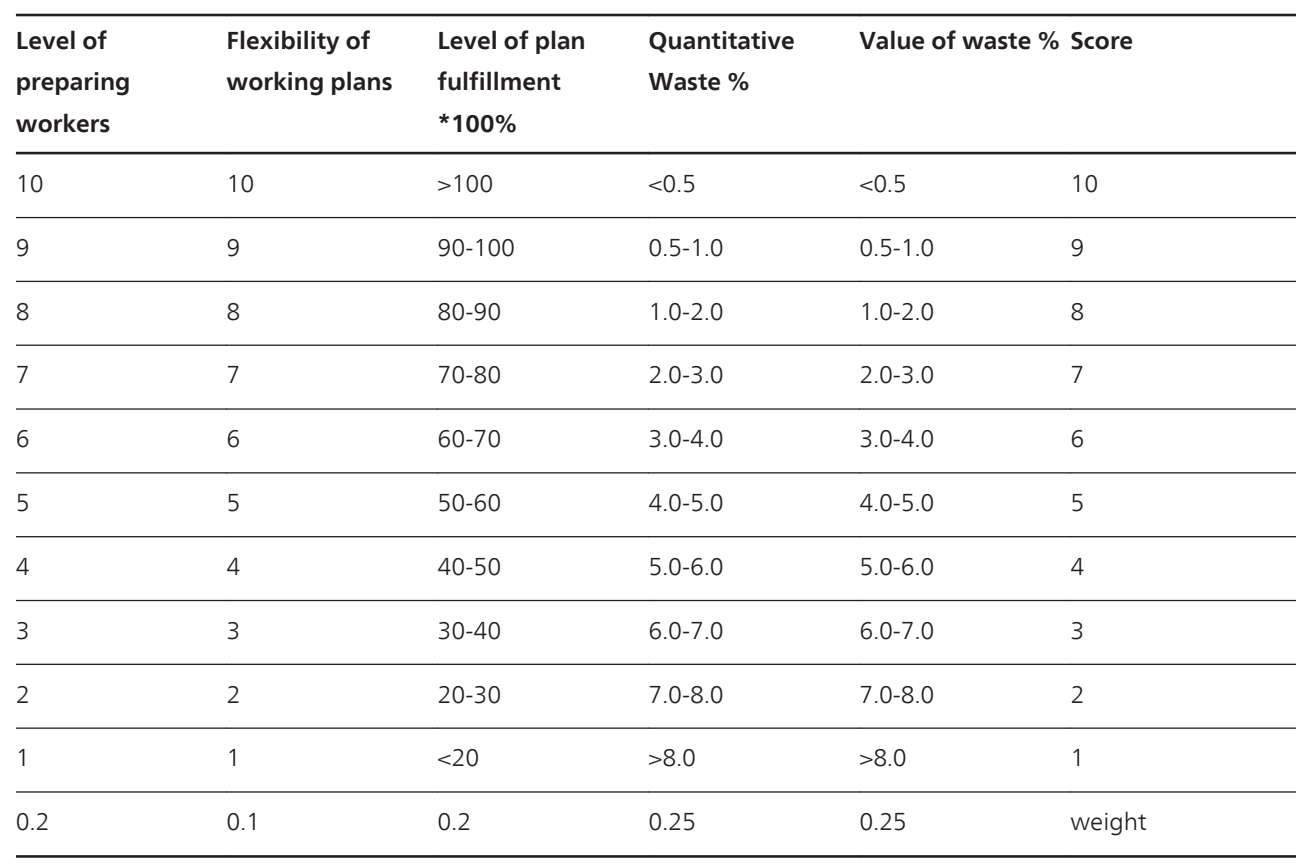

Table 2. Quality metrics of "Production process realization" KP 2.2 


\begin{tabular}{lllll}
\hline $\begin{array}{l}\text { Accuracy of demand Accuracy of MRP } \\
\%\end{array}$ & $\begin{array}{l}\text { Work in progress } / \\
\text { production } \\
\%\end{array}$ & $\begin{array}{l}\text { On time delivery } \\
\text { (OTD) } \\
\%\end{array}$ & Score \\
\hline $85-95$ & $85-95$ & $5-10$ & $90-95$ & 9 \\
\hline $75-85$ & $75-85$ & $10-15$ & $85-90$ & 8 \\
\hline $65-75$ & $65-75$ & $15-20$ & $80-85$ & 7 \\
\hline $55-65$ & $55-65$ & $20-25$ & $75-80$ & 6 \\
\hline $45-55$ & $45-55$ & $25-30$ & $70-75$ & 4 \\
\hline $35-45$ & $35-45$ & $30-35$ & $65-70$ & 3 \\
\hline $25-35$ & $25-35$ & $35-40$ & $60-65$ & 2 \\
\hline $15-25$ & $15-25$ & $40-45$ & $55-60$ & 1 \\
\hline$<15$ & $<15$ & $>45$ & $<55$ & weight \\
\hline 0.15 & 0.25 & 0.3 & 0.3 &
\end{tabular}

Table 3. Quality metrics of "Production process planning and scheduling" KP 2.3

\begin{tabular}{lllll}
\hline $\begin{array}{l}\text { Effectiveness of } \\
\text { control of inputs } \%\end{array}$ & $\begin{array}{l}\text { Effectiveness of } \\
\text { process control } \%\end{array}$ & $\begin{array}{l}\text { Effectiveness of } \\
\text { control of outputs } \%\end{array}$ & $\begin{array}{l}\text { Level of control } \\
\text { of measurement devices \% }\end{array}$ & Score \\
\hline$>95$ & $>95$ & $>95$ & 10 & 10 \\
\hline $85-95$ & $85-95$ & $90-95$ & 9 & 9 \\
\hline $75-85$ & $75-85$ & $85-90$ & 8 & 8 \\
\hline $65-75$ & $65-75$ & $80-85$ & 7 & 7 \\
\hline $55-65$ & $55-65$ & $75-80$ & 6 & 6 \\
\hline $45-55$ & $45-55$ & $70-75$ & 5 & 4 \\
\hline $35-45$ & $35-45$ & $65-70$ & 4 & 3 \\
\hline $25-35$ & $25-35$ & $60-65$ & 3 & 2 \\
\hline $15-25$ & $15-25$ & $55-60$ & 2 & 1 \\
\hline$<15$ & $<15$ & $<55$ & 1 & weight \\
\hline 0.25 & 0.25 & 0.3 & 0.2 & \\
\hline
\end{tabular}

Table 4. Quality metrics of "Production process control" KP 2.4 
Production process control (KP 2.4) could be decomposed into the following sub processes: Control of inputs; Process control, Control of outputs, Non conformance product control and Control of measurement devices. The accompanied quality metrics are presented in table 4 .

Quality systems focus on the quality of what the organization in the food industry produces, the factors which will cause the organization to achieve its goals, the factors which might prevent it satisfying customers and the factors which might prevent it from being productive, innovative and profitable. To control, assure and improve quality there is a need to focus on certain goals, in the case of goals of the production process (KP2) of a typical company in the food industry we can define goals as the constituent of the previous sub process goals (figure 3 ).

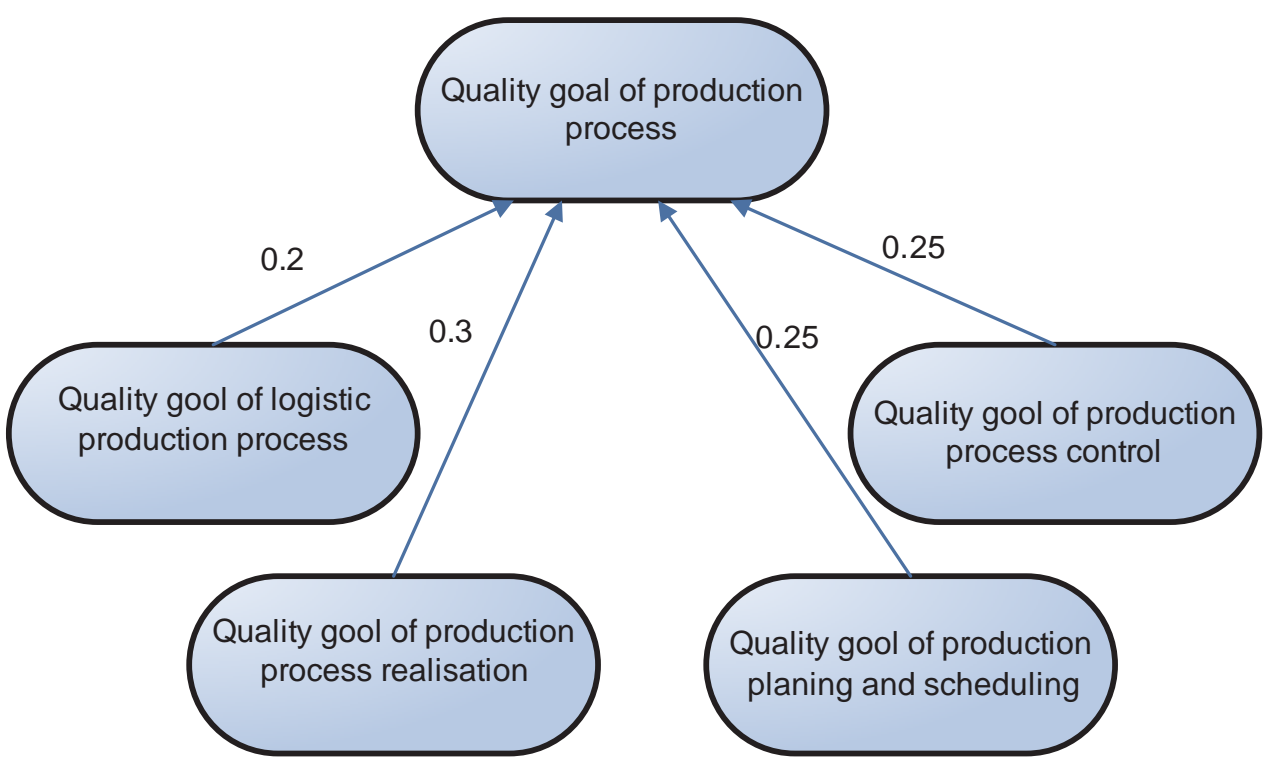

Figure 3. Quality goals of Production process KP2

By decomposition of the production process, analysis of sub processes and definition of metrics for each sub process it is possible to control, assure and improve the quality of a process in companies from the food industry sector. Definition of scores and weights in the metrics of each sub process is performed according to the authors' experience and available literature. In order to clearly demonstrate the idea all values are presented as deterministic ones. Of course some of them could be expressed by linguistic expressions rather than precious numbers but that issue will be elaborated in further text. The key processes in the food industry were analyzed and compared, and the results of research 
are presented in figure 4., depicting the existence of the gap between the quality of development and design process, and other processes. The analysis was performed on selected companies from Serbia.

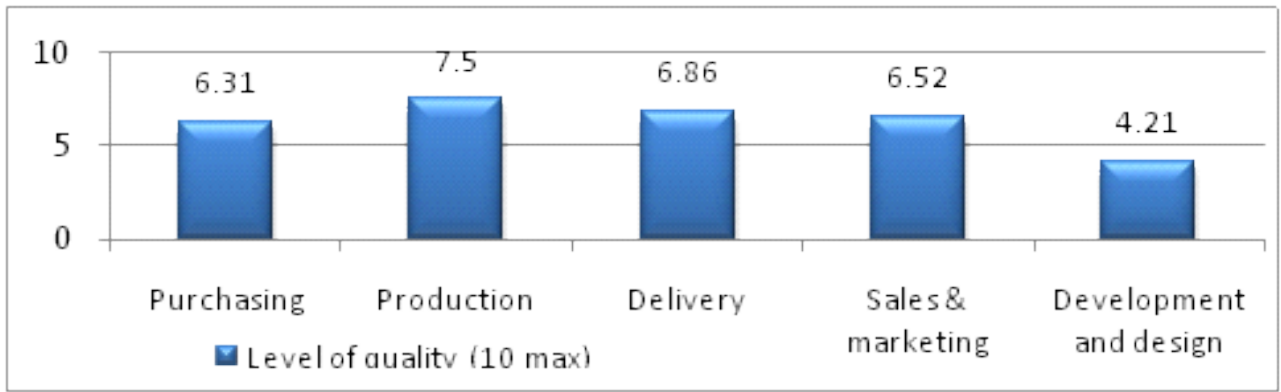

Figure 4. Quality of development and design process compared to quality of key processes

The gap between quality of the development and design process and other processes indicates that the quality of the development and design process is lower than the quality of the other processes so the focus in process redesign and improvement should be on the redesign of process development and design.

\section{Redesign of process development}

\subsection{Redesign of process development: Different approaches}

The redesign of process development is connected to different methodologies of process change. In the redesign of process development and in the process of business process redesign itself there are a number of methodologies which cover the different amount of changes, results, used tools and probability of success. According to [11], and presented in table 5 a comparison of possible methodologies indicating whether they are applicable in the food industry.

According to table 5 it is clear that Continuous Process Improvement (CPI) as a never ending effort to discover, and eliminate the main causes of problems, is most likely to succeed in companies from the food industry.

Process improvement and BPR \& lean are less likely to succeed but they cover a larger number of changes in the companies. Beside a redesign of process development can be viewed as a process. According to [11], the redesign of process development is divided into 5 phases (4 different entities) (Fig.5) with 10 steps. 


\begin{tabular}{|c|c|c|c|c|c|c|}
\hline No. & $\begin{array}{l}\text { Change } \\
\text { methodology }\end{array}$ & $\begin{array}{l}\text { Amount } \\
\text { of change }\end{array}$ & $\begin{array}{l}\text { Score } \\
\text { of change }\end{array}$ & Used tools & 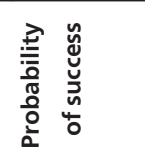 & 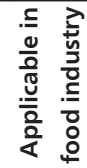 \\
\hline 1 & BPR \& lean & $\begin{array}{l}\text {-reduction more } \\
\text { than } 50 \% \text { of time, } \\
\text { costs and quality }\end{array}$ & $\begin{array}{l}\text {-cross func. teams } \\
\text { or } \\
\text { functional teams }\end{array}$ & $\begin{array}{l}\text {-process maps } \\
\text {-design principles } \\
\text {-benchmarking } \\
\text {-best practices } \\
\text {-lean tools }\end{array}$ & $\begin{array}{l}\text {-less than } \\
40 \%\end{array}$ & yes \\
\hline 2 & $\begin{array}{l}\text { Process } \\
\text { improvement }\end{array}$ & $\begin{array}{l}\text {-reduction more } \\
\text { than } 20 \% \text { of time, } \\
\text { costs and quality }\end{array}$ & $\begin{array}{l}\text {-cross teams or } \\
\text { functional teams }\end{array}$ & $\begin{array}{l}\text {-process maps } \\
\text {-design principles } \\
\text {-LE } \\
\text {-six sigma } \\
\text {-lean tools }\end{array}$ & $\begin{array}{l}\text {-more than } \\
70 \%\end{array}$ & yes \\
\hline 3 & $\begin{array}{l}\text { Continuous } \\
\text { process } \\
\text { improvement }\end{array}$ & $\begin{array}{l}\text {-small reduction } \\
\text { more than } 20 \% \text { of } \\
\text { time, costs and } \\
\text { quality }\end{array}$ & $\begin{array}{l}\text {-one person or } \\
\text { one sub process }\end{array}$ & & $\begin{array}{l}\text {-more than } \\
90 \%\end{array}$ & yes \\
\hline
\end{tabular}

Table 5. Comparison of change methodologies (adapted from [11])

There are five phases in this model:

- Analysis Phase - Identify areas of opportunity and target specific problems.

- Design Phase - Generate solutions and identify the required resources to implement the chosen solution with approval of senior management.

- Development Phase - Formulate a detailed procedure for implementing the approved solution with staff and customers.

- Implementation Phase - Execution of the solution and implementation of the redesign.

- Evaluation Phase - Build metrics, measurement tools, monitor implementation, and evaluate measurements for continuous improvement.

Process redesign as a process could be presented in the 10 steps, according to figure 5 . The first five steps are common for most companies and the other steps could be defined according to the specific problem and in some cases using different quality methods and tools.

The first step covers:

- Meeting with senior management for the purpose of discussing barriers to process,

- Improvement, problem of eventual job losses and crafting of the kick-off-speech,

- Meeting with affected process managers and employees. 
The second step is very important for success of the complete process. It is realized according to the team engineering approach $[12,13]$ with specified roles of team members: project manager, project principal, process improvement team, facilitator, and expert in ICT.

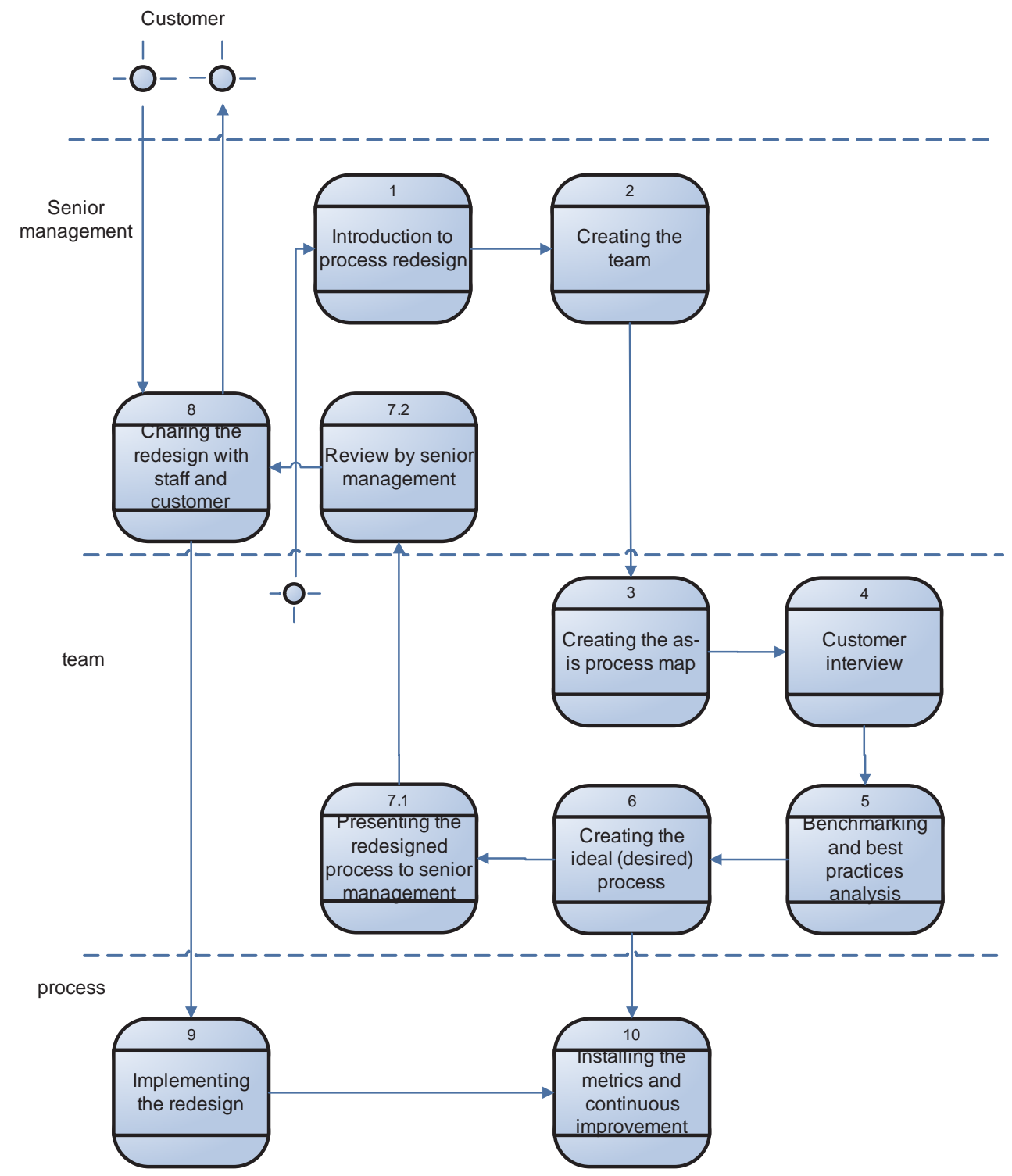

Figure 5. Process redesign as process 
Senior management has the important task of directing team work in the first meetings and by the definition of statements and roles which will define the procedures for the team work.

The third step is performed by team work, starting from analysis of the existing state of processes, best practice and creating the as-is state of processes.

The fourth step covers the interviews with customers, according to: Customer request and needs; Ranking the criteria; Needed performance according to each criteria and Competitor position according to ranking and criteria.

The use of benchmarks and the development of new forms of benchmarking for best practice is well established in the food industry, although less so in other areas of the food chain. Benchmarking and best practice analysis is performed in step five through analysis of food industry competitions, using information from: industry trade associations (trade chambers etc.), industry studies, consultants' reviews, distributors, former employees, competitors themselves, published documents, indirect information sources from competitors, government sources, customers, supplies, and reverse - engineering products.

Other steps are performed according to appropriate redesign methodology adapted for each specific organization from the food industry. In addition, different quality engineering tools and methods could be employed in the following steps. It is important to emphasize that ICT could be used as a support during process redesign on the one hand, and on the other hand ICT and Business Process Management cover various aspects such as process control and supply chain management.

\subsection{Quality engineering methods and tools in the food industry}

Quality engineering methods and tools have an important role in the food industry because customers and markets demand proven high quality products and protection against low quality and unsafe products. On the other hand, the food industry needs to attain the quality that meets international standards for quality products. As it was mentioned the food industry needs to cope with the challenge of modern technological production methods, know them and assimilate them in quality assurance areas using new innovative hi-tech sensory and measurement instruments, supervise the production process, so that the designated quality level is always met. In order to perform all of these tasks and in order to meet all of the existing challenges the food industry has a number of engineering methods and tools available.

We analyzed companies from Serbia (listed in the following text) and compared results with world practice. The following quality engineering methods and tools used by the food industry have been analyzed according to their frequency and success rate: (1) Ichicawa's seven basic tools for quality (flow chart, check sheet, histograms, scatter plots, control chart, cause-effect diagram, Pareto analysis); (2) The seven new tools for improvement (affinity diagram, interrelationship diagram, tree diagram, prioritization grid, matrix diagram, process decision program chart, activity network diagram) ; (3) Cost of Quality (CoQ) ; (4) Project management; (5) Simultaneous engineering; (6) Statistical process control; (7) Reliability and 
risk engineering; (8) World class manufacturing (WCM) ; (9) Six-sigma; (10) Lean six-sigma; (11) Taguchi method; (12) Zero defect (ZD) ; (13) Design of experiments; (14) Quality Function Deployment (QFD) ; (15) FMEA; (16) FMECA; (17) Just in Time (JiT) ; (18) Business Process Reengineering; (19) Balance Score Cards (BSC) ; and (20) other.

The results of the usage and frequency of the specific quality engineering methods and tools listed above, in the case of the Serbian food industry, is presented in Figure 6.

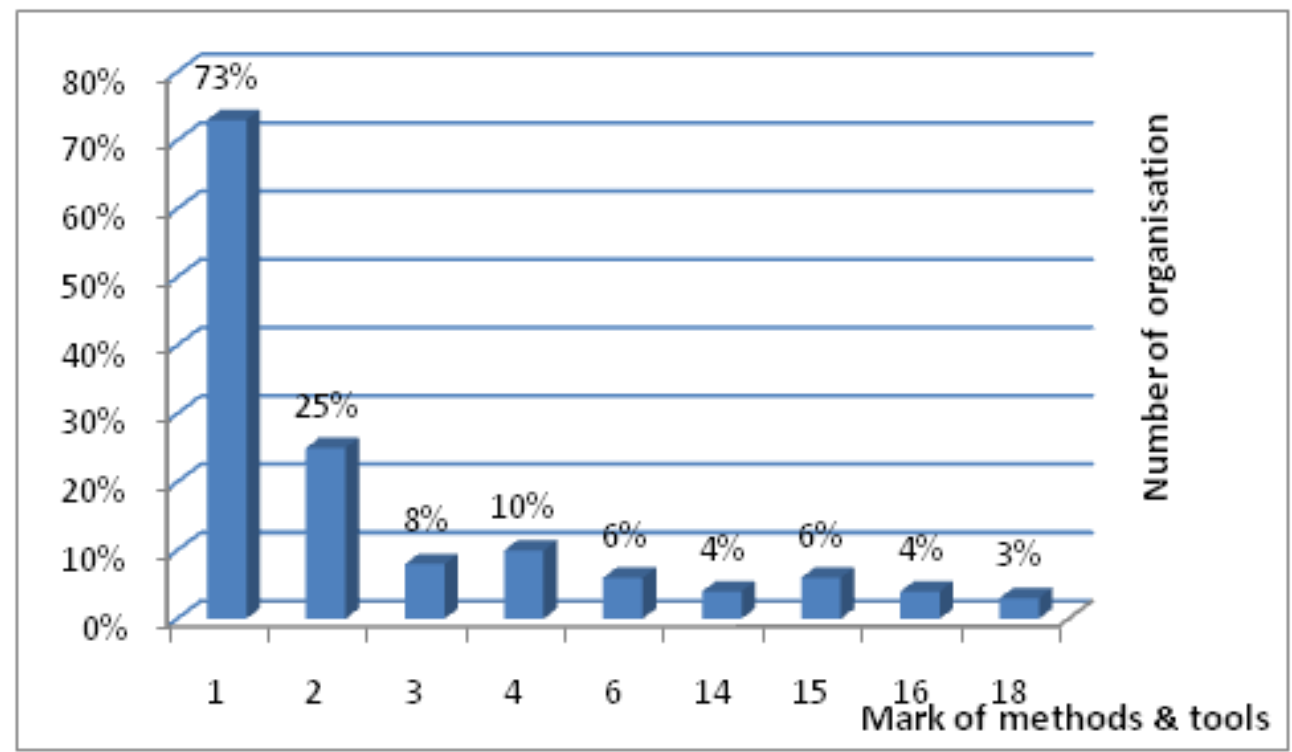

Figure 6. Distribution of quality methods' \& tools' application

According to the results of the research, presented in figure 6, the dominant method or tool in food companies in Serbia position have Ichicawa's seven basic tools for quality (flow chart, check sheet, histograms, scatter plots, control chart, cause-effect diagram, Pareto analysis). It is also obvious that Serbian companies in general do not employ (at sufficient level) more advanced, new methods needed for higher quality process improvement.

Project management and FMEA are also popular in Serbian food processing companies. The second question is an analysis of profit compared with the quality tools and methods. According to research there is a high positive correlation between an increase of profit and application of quality tools and methods and it is presented in figure 7.

According to figure 7 the level of profit (per employee) increases with implementation of different quality methods and tools. The largest increase in profit can be seen in the application of: Cost of Quality (CoQ), Statistical process control, Business Process Reengineering. The increase in the profit with the application of seven new tools is larger than with the application of the basic seven tools for quality. It is interesting that the basic seven tools for 
quality are the most commonly used but their contribution to profit increase is the lowest compared with other frequently used quality methods and tools. Another result is that the seven new tools do not contribute more significantly to the increase of profit due to the lower level of knowledge of employees connected with the new approaches.

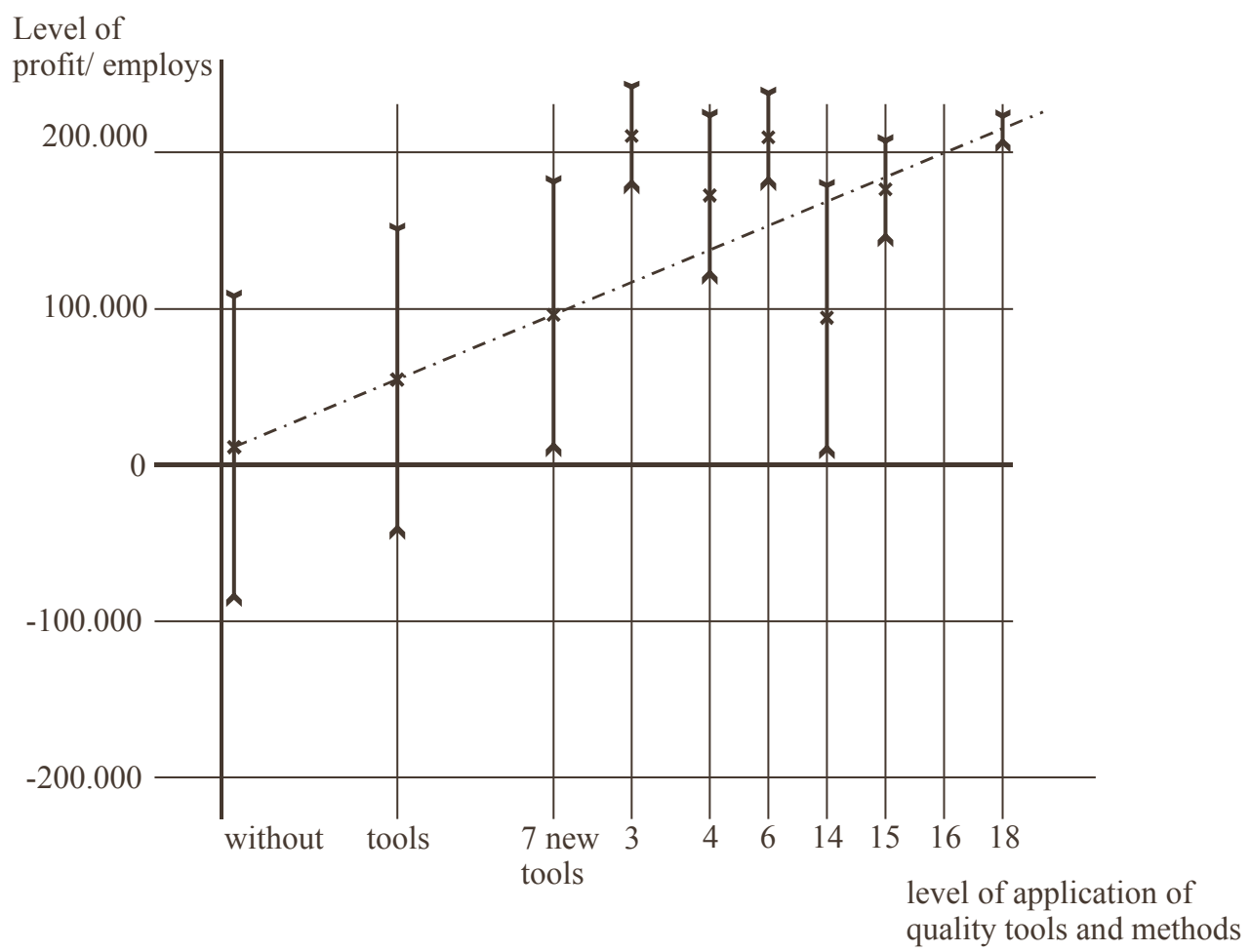

Figure 7. Impact of level of application of quality tools and methods on profit/employee

Finally, although rather "old" QFD proved itself as a very useful and efficient tool. Generally, with an increase of the level of application of quality tools and methods profit/employees increases in the analyzed organizations.

\subsection{Fuzzy approach for evaluation of the importance of entities in supply chains in the food industry}

The process of logistics and the food supply chain is very important for all companies from the food industry. In food supply chains, definition of weight / importance of different entities (processes, sub processes and goals) in the presence of uncertainties is one of the important goals for the management team. A similar problem has been met and emphasized in the definition of quality metrics and evaluation of scores and weights in section 2 . The solution 
to this problem must be placed on the whole of the supply chain because of its critical effect on efficiency.

It is realistic to assume, that decision makers express their evaluations more easy and more precisely by using linguistic expressions than numbers. The number and the type of linguistic expression used for a description of importance are defined by the management team and depend on the size of supply chain in food companies. Different mathematical approaches such as probability theory, fuzzy sets, rough set theory and others enable quantification of linguistic expressions. The development of fuzzy set theory enables the elimination of uncertainties and imprecision caused by lack of good evidence. In the fuzzy approach the uncertainties and imprecision caused are described by linguistic variables. They can be modeled by fuzzy sets with a different shape (triangle, trapezoid, but in some cases with Gaussian distribution, discrete fuzzy numbers) of membership functions.

The fuzzy approach has been used in cases: (1) where conditions have been constantly changing so the observed value could not be stochastically described (2) where there is no sufficient amount of data for statistical analysis. In other words, fuzzy sets theory could simulate human way of thinking in the process of decision making under imprecise, approximative and unclear data.

According to [14] the advantages of fuzzy sets theory can be presented in the following: it is conceptually clear, flexible, covers different non-linear functions of different complexity; tolerant on imprecise data; includes expert opinions and viewpoints; based on natural language; enables better communication between experts and managers.

Estimation of the relative importance of the processes and sub processes on the level of the supply chain $\mathrm{p} \in \mathrm{P}$ is defined by a pair-wise comparison matrix whose elements are defined as the relative importance of process/sub-process $i / j$ compared to process/sub-process $i^{\prime} / j^{\prime}, i, i,{ }^{\prime}=1, . ., I ; j, j^{\prime}=1, . ., J_{i}$ where $\mathrm{I}$ and,$J_{i}$ are the total number of analyzed processes and sub processes $\mathrm{i}, \mathrm{i}(1, . . \mathrm{I}$, respectively). A number of authors consider this approach better compared to direct estimation. Elements of the pair-wise comparison matrix are linguistic expressions which are modeled by triangular fuzzy numbers [14, 15]. The domains of these fuzzy numbers are defined on interval [1-5]. Value 1, or value 5 define that analyzed entity $i / j$ compared to entity $i^{\prime} / j^{\prime}, i, i,{ }^{\prime}=1, . ., I ; j, j{ }^{\prime}=1, . ., J_{i}$ has the same or extremely higher importance retrospectively. These triangular fuzzy numbers are defined as: Very low importance $\tilde{R}_{1}=(x ; 1,1,2)$ Low importance $-\tilde{R}_{2}=(x ; 1,1,3)$, Medium importance $-\tilde{R}_{3}=(x ; 1,3,5)$, High importance $-\tilde{R}_{4}=(x ; 3,5,5)$ and Very high importance- $\tilde{R}_{5}=(x ; 4,5,5)$.

The weights vector can be calculated by applying fuzzy extent analysis [16]. The weights vector of processes is denoted as $W=\left(w_{1}, . ., w_{i}, \ldots, w_{I}\right)$ and sub processes $W_{i}=\left(w_{i 1}, . ., w_{i j}, \ldots, w_{i j}\right)$. The relative importance of processes $w_{i}$ and sub-processes $w$ are ordinal numbers. In literature, there are many papers in which the weights vector is given by applying extent analysis [17]. 
The importance of the goals which are defined on the level of each sub process are defined by direct estimation made by a management team. According to literature, it can be concluded that this approach of estimation of importance of an entity is justified when the number of entities is less than five.

The importance of each goal $\mathrm{k}, \mathrm{k}=1, ., K_{i j}$ on the level of sub process $\mathrm{j}, \mathrm{j}=1, . ., J_{i}$ could be described using five linguistic expressions which are modeled by triangular fuzzy numbers $\tilde{v}_{i j k}=\left(y ; l_{i j k}, m_{i j k}, u_{i j k}\right)$. The total number of goals on the level of each sub process is denoted as $K_{i j}$. The value of domains is defined on a standard measurement scale [18]. These triangular fuzzy numbers are defined in the following way: very low value- $(y ; 1,1,3)$, low value$(y ; 1,3,5)$, medium value- $(y ; 3,5,7)$, high value- $(y ; 5,7,9)$ and very high value$(y ; 8,9,9)$. Since the goals could be beneficial or costly it is necessary to perform normalization of fuzzy values $\tilde{v}_{i j k}, i=1, . ., I ; j=1, . ., J_{i} ; k=1, . ., K_{i j}$. In this case the procedure of linear normalization is used [16]. Normalized values of goals weights are marked as $\tilde{r}_{i j k}, i=1, . ., I ; j=1, . ., J^{i}, k=1, . ., K_{i j}$. In further analysis only one goal with a critical effect on the management of sub-process $\mathrm{j}, \mathrm{j}=1, . ., J_{i}$ is considered.

For the management team carrying out the analysis, the following tasks are important: (1) to determine the rank of the process in a company (2) to determine the rank of a sub process on the process level in a company, (3) to determine the rank of sub processes with respect to the importance of goals and the importance of the considered sub process (4) to determine the rank of processes with respect to the importance of the goals, the relative importance of subprocesses of process $i, i=1, . . I_{m}$ and the relative importance of process $i, i=1, . . I$, and (5) calculate the degree of belief that the sub process, or process which is on second place in the rank could be on first place; answers to these questions are given by comparing triangular fuzzy numbers $\tilde{c}_{i j}, \tilde{d}_{i}, i=1, . ., I ; j=1, . ., J_{i}$, respectively.

The algorithm for analysis of the relative importance of processes, sub-processes and goals in a company $\mathrm{p} \in \mathrm{P}$ is formally given as follows.

Step 1. Input fuzzy matrix $\tilde{W}=\left[\tilde{w}_{i i}\right], i, i^{\prime}=1, . ., I ; i \neq i ; p=1, \ldots, P$

Step 2. Calculate weight vector $W=\left(w_{1}, . ., w_{i}, \ldots, w_{I}\right)$; rank the processes by placing on first place the process with highest $w_{i}$.

Step 3. Calculate weight vector $W_{i}=\left(w_{i 1}, . ., w_{i j}, \ldots, w_{i j}{ }^{i}\right)$; rank sub processes on the level of each process $\mathrm{i}, \mathrm{i}=1, . ., \mathrm{I}$ by placing on the first place the sub process with the highest value $w_{i j}$.

Step 4. Transform all linguistic expressions which are modeled by triangular fuzzy numbers $\tilde{v}_{i j k}$ into $\tilde{r}_{i j k}=\left(z ; L_{i j k}, M_{i j k}, U_{i j k}\right)$ by applying linear normalization procedure [16].

Step 5. Calculate the weighted normalized aggregated relative importance of sub-process j: 
$\tilde{c}_{i j}=\frac{1}{K_{i j}} \cdot \sum_{k=1}^{K_{i j}} w_{i j} \cdot \tilde{r}_{i j k} i=1, . ., I ; j=1, . ., J^{i}, k=1, . ., K_{i j}$

Step 6. Calculate the weighted normalized aggregated relative importance of process i: $\tilde{c}_{i}=\frac{1}{J_{i}} \cdot \sum_{j=1}^{J_{i}} w_{i} \cdot \tilde{c}_{i j}, \quad i=1, . ., I ; j=1, . ., J^{i}$

Step 7. Rank sub-processes and processes according to decreasing order, $\tilde{c}_{i j}$ and $\tilde{d}_{i}$, respectively and define level of belief that sub-process $\mathrm{j}, \mathrm{j}=1, \ldots, J_{i}$, or process $\mathrm{i}, \mathrm{i}=1, . ., \mathrm{I}$ could have the highest importance with respect to the importance of all goals and the importance of sub process $\mathrm{j}, \mathrm{j}=1, \ldots, J_{i}$, or process $\mathrm{i}, \mathrm{i}=1, . ., \mathrm{I}[19]$.

The developed procedure is illustrated with an example with real-life data from the authors' research.

The pair-wise comparison matrix of relative importance of processes is:

$$
\left[\begin{array}{ccc}
1,1,1 & 1 / \tilde{R}_{3} & \tilde{R}_{2} \\
\tilde{R}_{3} & 1,1,1 & \tilde{R}_{3} \\
1 / \tilde{R}_{2} & 1 / \tilde{R}_{3} & 1,1,1
\end{array}\right]
$$

The weight vector of processes is:

$W=\left(\begin{array}{llllllll}0.015 & 0.072 & 0.114 & 0.114 & 0.171 & 0.171 & 0.171 & 0.171\end{array}\right)$

The most important processes in considered food company are: Project execution (i=5), Process execution ( $\mathrm{i}=6)$, Quality assurance $(\mathrm{i}=7)$ and Support processes $(\mathrm{i}=8)$.

The pairwise comparison matrix of relative importance of subprocesses under process $i=1$ is:

$$
\left[\begin{array}{cccccccc}
1,1,1 & 1 / \tilde{R}_{1} & 1 / \tilde{R}_{3} & 1 / \tilde{R}_{3} & 1 / \tilde{R}_{4} & 1 / \tilde{R}_{4} & 1 / \tilde{R}_{4} & 1 / \tilde{R}_{4} \\
\tilde{R}_{1} & 1,1,1 & 1 / \tilde{R}_{2} & 1 / \tilde{R}_{2} & 1 / \tilde{R}_{3} & 1 / \tilde{R}_{3} & 1 / \tilde{R}_{3} & 1 / \tilde{R}_{3} \\
\tilde{R}_{3} & \tilde{R}_{2} & 1,1,1 & 1,1,1 & 1 / \tilde{R}_{3} & 1 / \tilde{R}_{3} & 1 / \tilde{R}_{3} & 1 / \tilde{R}_{3} \\
\tilde{R}_{3} & \tilde{R}_{2} & 1,1,1 & 1,1,1 & 1 / \tilde{R}_{3} & 1 / \tilde{R}_{3} & 1 / \tilde{R}_{3} & 1 / \tilde{R}_{3} \\
\tilde{R}_{4} & \tilde{R}_{3} & \tilde{R}_{3} & \tilde{R}_{3} & 1,1,1 & 1,1,1 & 1,1,1 & 1,1,1 \\
\tilde{R}_{4} & \tilde{R}_{3} & \tilde{R}_{3} & \tilde{R}_{3} & 1,1,1 & 1,1,1 & 1,1,1 & 1,1,1 \\
\tilde{R}_{4} & \tilde{R}_{3} & \tilde{R}_{3} & \tilde{R}_{3} & 1,1,1 & 1,1,1 & 1,1,1 & 1,1,1 \\
\tilde{R}_{4} & \tilde{R}_{3} & \tilde{R}_{3} & \tilde{R}_{3} & 1,1,1 & 1,1,1 & 1,1,1 & 1,1,1
\end{array}\right]
$$


The weight vector of sub-processes on level process $\mathrm{i}=1$ is:

$W_{1}=\left(\begin{array}{lll}0.295 & 0.497 & 0.208\end{array}\right)$

Sub process under process is "Strategic choice" $(j=2)$.

The pairwise comparison matrix of relative importance of subprocesses under process $i=2$ is:

$$
\left[\begin{array}{ccccccc}
1,1,1 & 1 / \tilde{R}_{2} & 1 / \tilde{R}_{2} & 1 / \tilde{R}_{3} & 1 / \tilde{R}_{2} & 1,1,1 & 1,1,1 \\
\tilde{R}_{2} & 1,1,1 & 1,1,1 & 1 / \tilde{R}_{2} & 1,1,1 & \tilde{R}_{2} & \tilde{R}_{3} \\
\tilde{R}_{2} & 1,1,1 & 1,1,1 & \tilde{R}_{2} & 1,1,1 & \tilde{R}_{2} & \tilde{R}_{3} \\
\tilde{R}_{3} & \tilde{R}_{2} & \tilde{R}_{2} & 1,1,1 & \tilde{R}_{2} & \tilde{R}_{3} & \tilde{R}_{4} \\
\tilde{R}_{2} & 1,1,1 & 1,1,1 & 1 / \tilde{R}_{2} & 1,1,1 & \tilde{R}_{2} & \tilde{R}_{3} \\
1,1,1 & 1 / \tilde{R}_{2} & 1 / \tilde{R}_{2} & 1 / \tilde{R}_{3} & 1 / \tilde{R}_{2} & 1,1,1 & \tilde{R}_{2} \\
1 / \tilde{R}_{1} & 1 / \tilde{R}_{3} & 1 / \tilde{R}_{3} & 1 / \tilde{R}_{4} & 1 / \tilde{R}_{3} & 1 / \tilde{R}_{2} & 1,1,1
\end{array}\right]
$$

The weight vector of sub-processes on level process $i=2$ is:

$W_{2}=\left(\begin{array}{lllllll}0.095 & 0.165 & 0.178 & 0.229 & 0.165 & 0.107 & 0.061\end{array}\right)$

Sub process under process is "Level of leadership transformation" ( $j=4)$.

The pairwise comparison matrix of relative importance of subprocesses under process $i=3$ is:

$$
\left[\begin{array}{cccc}
1,1,1 & \tilde{R}_{2} & \tilde{R}_{3} & \tilde{R}_{3} \\
1 / \tilde{R}_{2} & 1,1,1 & \tilde{R}_{2} & \tilde{R}_{2} \\
1 / \tilde{R}_{3} & 1 / \tilde{R}_{2} & 1,1,1 & 1,1,1 \\
1 / \tilde{R}_{3} & 1 / \tilde{R}_{2} & 1,1,1 & 1,1,1
\end{array}\right]
$$

The weight vector of sub-processes on level process $i=3$ is:

$W_{3}=\left(\begin{array}{llll}0.39 & 0.275 & 0.168 & 0.168\end{array}\right)$

Subprocess under process is "Roles and responsibilities" ( $\mathrm{j}=1$ ). 
The pairwise comparison matrix of relative importance of subprocesses under process $i=4$ is:

$$
\left[\begin{array}{ccccccc}
1,1,1 & 1 / \tilde{R}_{2} & 1,1,1 & 1 / \tilde{R}_{2} & 1,1,1 & 1 / \tilde{R}_{2} & 1 / \tilde{R}_{3} \\
\tilde{R_{2}} & 1,1,1 & \tilde{R}_{2} & 1,1,1 & \tilde{R}_{2} & 1,1,1 & 1 / \tilde{R}_{2} \\
1,1,1 & 1 / \tilde{R}_{2} & 1,1,1 & 1 / \tilde{R}_{2} & 1,1,1 & 1 / \tilde{R}_{2} & 1 / \tilde{R}_{3} \\
\tilde{R}_{2} & 1 / \tilde{R}_{2} & \tilde{R}_{2} & 1,1,1 & 1 / \tilde{R}_{2} & 1,1,1 & 1 / \tilde{R}_{2} \\
1,1,1 & 1 / \tilde{R}_{2} & 1,1,1 & \tilde{R}_{2} & 1,1,1 & 1 / \tilde{R}_{2} & 1 / \tilde{R}_{3} \\
\tilde{R}_{2} & 1,1,1 & \tilde{R}_{2} & 1,1,1 & \tilde{R}_{2} & 1,1,1 & 1 / \tilde{R}_{2} \\
\tilde{R}_{3} & \tilde{R}_{2} & \tilde{R}_{3} & \tilde{R}_{2} & \tilde{R}_{3} & \tilde{R}_{2} & 1,1,1
\end{array}\right]
$$

The weight vector of sub-processes on level process $i=4$ is:

$W_{4}=\left(\begin{array}{lllllll}0.1 & 0.155 & 0.1 & 0.144 & 0.123 & 0.155 & 0.222\end{array}\right)$

Sub-process under process $\mathrm{i}=4$ is "Process significance". $(\mathrm{j}=7)$.

Processes $i=5$ and $i=6$ could be decomposed on four sub processes each. The relative importance of sub processes under process $i=5$ and $i=6$ are equal. Such that $w_{5 j}=w_{6 j}=0.25, \quad j=1,2,3,4$.

The pairwise comparison matrix of relative importance of subprocesses under process $i=7$ is:

$$
\left[\begin{array}{ccccc}
1,1,1 & 1 / \tilde{R}_{3} & 1 / \tilde{R}_{4} & 1 / \tilde{R}_{4} & 1 / \tilde{R}_{3} \\
\tilde{R}_{3} & 1,1,1 & 1 / \tilde{R}_{3} & 1 / \tilde{R}_{3} & 1,1,1 \\
\tilde{R}_{4} & \tilde{R}_{3} & 1,1,1 & 1,1,1 & \tilde{R}_{2} \\
\tilde{R}_{4} & \tilde{R}_{3} & 1,1,1 & 1,1,1 & \tilde{R}_{2} \\
\tilde{R}_{3} & 1,1,1 & 1 / \tilde{R}_{2} & 1 / \tilde{R}_{2} & 1,1,1
\end{array}\right]
$$

The weight vector of sub-processes on level process $i=7$ is:

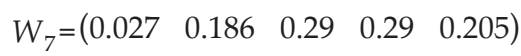

Sub process under process $\mathrm{i}=7$ is "Level of accomplishment of quality goals". $(\mathrm{j}=3)$.

Process $i=8$ could be decomposed on eight sub processes. According to the fuzzy rating of the management team, all sub processes have equal of the relative importance, so that $w_{8 j}=0.143, \quad j=1, \ldots, 8$.

Estimation of the importance of goals with critical effect management of the sub processes are given in Table 6. By applying the Algorithm (Step 5 to Step 7) rank of sub processes with respect to the relative importance of the defined goals and the relative importance of the sub 
processes and the rank of the processes with respect to the relative importance of the sub processes and the relative importance of processes is determined. The calculated ranks are presented in Table 7 and Table 8.

According to the calculated values of importance of the sub processes with respect to their relative importance and the relative importance of the goals of each sub process (see Table 2) the following analysis can be made: The sub process which has the highest importance: (1) Strategic alignment ( $\mathrm{i}=1$ ) is Strategic choice $(\mathrm{j}=2)$, (2) Process development $(\mathrm{i}=4)$ is Process significance $(j=7)$ and (3) Quality assurance of goals $(j=3)$ and documentation of the process $(j=4)$. Based on the calculated degree of belief it is clear that the other sub processes, $i=1, i=4$ and $i=7$ have very low importance compared to the first ranked sub process.

\begin{tabular}{|c|c|c|c|c|c|}
\hline $\begin{array}{l}\mathrm{ijk}, \mathrm{i}=1, \ldots, \mathrm{I} ; \mathrm{j}=1, \ldots, J_{i} \\
\mathrm{k}=1, . ., K_{i j}\end{array}$ & $\tilde{v}_{i j k}$ & $\tilde{r}_{i j k}$ & $\begin{array}{l}\mathrm{ijk}, \mathrm{i}=1, . . \mathrm{l} ; \mathrm{j}=1, \ldots, J_{i} \\
\mathrm{k}=1, . ., K_{i j}\end{array}$ & $\tilde{v}_{i j k}$ & $\tilde{r}_{i j k}$ \\
\hline 111 & low value & $(0.11,0.11,0.33)$ & 511 & high value & $(0.56,0.78,1)$ \\
\hline 122 & medium value & $(0.33,0.56,0.78)$ & 522 & high value & $(0.56,0.78,1)$ \\
\hline 133 & very low value & $(0.11,0.11,0.33)$ & 533 & high value & $(0.56,0.78,1)$ \\
\hline 222 & medium value & $(0.33,0.56,0.78)$ & 544 & high value & $(0.56,0.78,1)$ \\
\hline 233 & high value & $(0.56,0.78,1)$ & 611 & high value & $(0.56,0.78,1)$ \\
\hline 244 & medium value & $(0.33,0.56,0.78)$ & 622 & very high value & $(0.89,1,1)$ \\
\hline 255 & medium value & $(0.33,0.56,0.78)$ & 633 & very high value & $(0.89,1,1)$ \\
\hline 266 & high value & $(0.56,0.78,1)$ & 644 & very high value & $(0.89,1,1)$ \\
\hline 277 & medium value & $(0.33,0.56,0.78)$ & 711 & high value & $(0.56,0.78,1)$ \\
\hline 311 & medium value & $(0.33,0.56,0.78)$ & 722 & very high value & $(0.89,1,1)$ \\
\hline 322 & medium value & $(0.33,0.56,0.78)$ & 733 & very high value & $(0.89,1,1)$ \\
\hline 333 & high value & $(0.56,0.78,1)$ & 744 & very high value & $(0.89,1,1)$ \\
\hline 344 & very high value & $(0.89,1,1)$ & 755 & very high value & $(0.11,0.11,0.12)$ \\
\hline 411 & high value & $(0.56,0.78,1)$ & 811 & high value & $(0.56,0.78,1)$ \\
\hline 422 & high value & $(0.56,0.78,1)$ & 822 & high value & $(0.56,0.78,1)$ \\
\hline 433 & very high value & $(0.89,1,1)$ & 833 & high value & $(0.56,0.78,1)$ \\
\hline 444 & high value & $(0.56,0.78,1)$ & 844 & high value & $(0.56,0.78,1)$ \\
\hline 455 & high value & $(0.56,0.78,1)$ & 855 & high value & $(0.56,0.78,1)$ \\
\hline 466 & high value & $(0.56,0.78,1)$ & 866 & medium value & $(0.33,0.56,0.78)$ \\
\hline 477 & very high value & $(0.89,1,1)$ & 877 & very high value & $(0.89,1,1)$ \\
\hline
\end{tabular}

Table 6. Importance of goals on the level of each sub process with the critical effect on management of those sub processes 


\begin{tabular}{|c|c|c|c|c|c|c|c|}
\hline $\begin{array}{l}i j, i=1, . ., l ; \\
j=1, . J\end{array}$ & $\tilde{c}_{i j}$ & 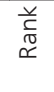 & $\begin{array}{l}\text { Degree of } \\
\text { belief }\end{array}$ & $\begin{array}{l}i j, i=1, . ., i \\
j=1, . . J_{i}\end{array}$ & $\tilde{c}_{i j}$ & 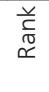 & Degree of belief \\
\hline 11 & $(0.032,0.097,0.165)$ & 2 & 0.005 & 51 & $(0.14,0.195,0.25)$ & 1 & \\
\hline 12 & $(0.164,0.278,0.388)$ & 1 & & 52 & $(0.14,0.195,0.25)$ & 1 & \\
\hline 13 & $(0.023,0.023,0.068)$ & 3 & & 53 & $(0.14,0.195,0.25)$ & 1 & \\
\hline 21 & $(0.031,0.053,0.074)$ & 5 & & 54 & $(0.14,0.195,0.25)$ & 1 & \\
\hline 22 & $(0.092,0.129,0.165)$ & 1 & & 61 & $(0.14,0.195,0.25)$ & 2 & 0.34 \\
\hline 23 & $(0.059,0.1,0.139)$ & 3 & & 62 & $(0.222,0.25,0.25)$ & 1 & \\
\hline 24 & $(0.076,0.128,0.179)$ & 2 & 0.99 & 63 & $(0.222,0.25,0.25)$ & 1 & \\
\hline 25 & $(0.092,0.129,0.165)$ & 1 & & 64 & $(0.222,0.25,0.25)$ & 1 & \\
\hline 26 & $(0.035,0.05,0.083)$ & 4 & & 71 & $(0.015,0.021,0.027)$ & 4 & \\
\hline 27 & $(0.02,0.034,0.048)$ & 6 & & 72 & $(0.165,0.185,0.185)$ & 2 & 0.00 \\
\hline 31 & $(0.129,0.218,0.304)$ & 1 & & 73 & $(0.258,0.29,0.29)$ & 1 & \\
\hline 32 & $(0.091,0.154,0.214)$ & 3 & & 74 & $(0.258,0.29,0.29)$ & 1 & \\
\hline 33 & $(0.094,0.131,0.168)$ & 4 & & 75 & $(0.023,0.023,0.026)$ & 3 & \\
\hline 34 & $(0.15,0.168,0.168)$ & 2 & 0.44 & 81 & $(0.08,0.112,0.143)$ & 2 & 0.34 \\
\hline 41 & $(0.056,0.078,0.1)$ & 6 & & 82 & $(0.08,0.112,0.143)$ & 2 & 0.34 \\
\hline 42 & $(0.087,0.121,0.155)$ & 2 & & 83 & $(0.08,0.112,0.143)$ & 2 & 0.34 \\
\hline 43 & $(0.089,0.1,0.1)$ & 4 & & 84 & $(0.08,0.112,0.143)$ & 2 & 0.34 \\
\hline 44 & $(0.081,0.112,0.144)$ & 3 & & 85 & $(0.08,0.112,0.143)$ & 2 & 0.34 \\
\hline 45 & $(0.069,0.096,0.123)$ & 5 & & 86 & $(0.055,0.08,0.112)$ & 3 & \\
\hline 46 & $(0.087,0.121,0.155)$ & 2 & 0.00 & 87 & $(0.127,0.143,0.143)$ & 1 & \\
\hline 47 & $(0.196,0.22,0.23)$ & 1 & & & & & \\
\hline
\end{tabular}

Table 7. Rank of sub-process with respect to the importance and goals of the sub process

Under the following processes, the sub processes which have the most importance are: (1) Process governance ( $\mathrm{i}=3$ )- Rules and responsibilities $(\mathrm{j}=1)$, (2) Process execution ( $\mathrm{i}=6)$ - Planned and achieved goals $(\mathrm{j}=2)$, Resource utilization $(\mathrm{j}=3)$, and Human resources $(\mathrm{j}=4)$, and (3) Support processes $(i=8)$ - ICT support $(j=7)$. Based on the degree of beliefs, the management team can conclude that the sub processes which are placed on second place in the rank under treated processes have less importance compared to the sub processes which are placed on first place. However, in making operational decisions, the importance of the sub processes which are on second place should be considered. The most important sub-process under Process leadership ( $i=2$ ) is Level of leadership transformation $(j=5)$. Since the degree of belief for the sub process Level of trust and communication in an organization ( $j=4)$ is 0.99 , it is clear that these two sub-processes have equal relative importance. 
Process execution is the most important process in the analyzed food processing companies according to analysis of the importance of all sub processes, the importance of the defined goals of the sub process and the importance of the process. The degree of belief that the process which is denoted as Project execution has the highest importance of 0.8 . According to the calculated result, the mentioned process has high importance for the specific food company, so the management team must have this in mind in making strategic decisions.

\begin{tabular}{|c|c|c|c|}
\hline $\begin{array}{l}i \\
i=1, . ., I\end{array}$ & $\tilde{d}_{i}$ & Rank & $\begin{array}{l}\text { Degree of belief that process has the highest } \\
\text { importance }\end{array}$ \\
\hline 1 & $(0.001,0.0 .002,0.003)$ & 4 & \\
\hline 2 & $(0.004,0.006,0.009)$ & 7 & \\
\hline 3 & $(0.013,0.019,0.024)$ & 5 & \\
\hline 4 & $(0.011,0.014,0.016)$ & 6 & \\
\hline 5 & $(0.024,0.033,0.043)$ & 2 & 0.8 \\
\hline 6 & $(0.1015,0.04,0.043)$ & 1 & \\
\hline 7 & $(0.025,0.028,0.028)$ & 3 & \\
\hline 8 & $(0.014,0.019,0.024)$ & 5 & \\
\hline
\end{tabular}

Table 8. Rank of process with respect to its importance and importance of goals of the sub-process of each process

The presented model is used for the development of a very usable software solution that enables calculation of the importance of each goal, process and sub process [20,21].

\subsection{Strategy map}

A strategy map describes how an organization can create sustained value for its shareholders, customers and communities.

The strategy map is developed based on the Kaplan and Norton model. A Strategy map describes how the organization creates value by connecting strategy objectives in an explicit cause and effect relationship in the four BSC objectives (financial, customer, processes, learning and growth). Strategy map is a strategic part of the BSC (Balanced Score Card) framework to describe strategies for value creation.

- Financial perspective is recognized in competitiveness.

- Customer perspective is identified: (1) quality, (2) safety, and (3) image.

- Internal perspective's eight processes: (P1) strategy alignment, (P2) process leadership, (P3) process governance, (P4) process development, (P5) project execution, (P6) process execution, (P7) quality assurance process, and (P8) supporting processes.

- Perspective or growth and learning: (1) technology and (2) people capability. 


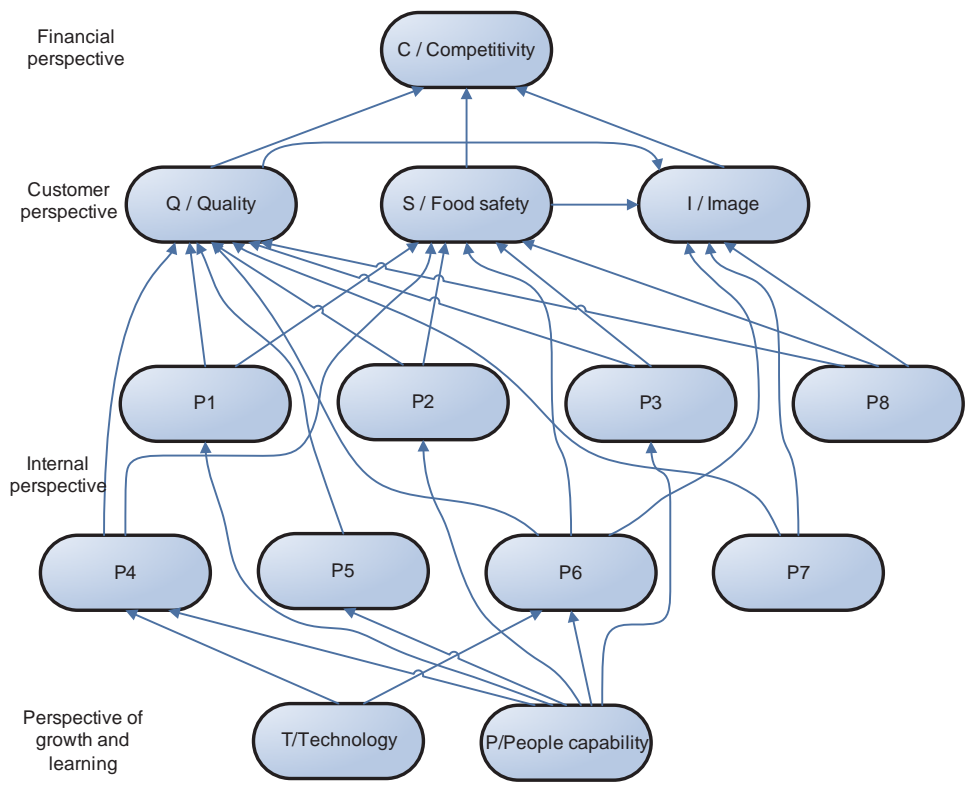

Figure 8. Strategy map

A strategy map for the food industry is presented in figure 8. The level of each component process is identified using a questioner for companies in the Serbian food industry. Relations among processes are defined using a method with 3 iterations.

A strategic map should describe a strategy and present the strategy to management and employees, and in the same way connect stakeholders, customer management, process management, quality management, core capabilities, innovations, human resources, ICT, organizational design / redesign and learning.

\section{Research results: Case study of the serbian food industry}

\subsection{Proposed model: Process framework for companies in the food industry}

In this section we will provide the process framework for companies from the food industry sector. All processes are divided into the following categories: leadership processes, core processes and support processes. As it was shown in the section above "Project execution" process (P5) has the highest importance.

The support processes contain the following: CRM (Customer Relation Management), Supply management, Human resources management, ICT support, Maintenance, Marketing, Sales, Finances, Quality management and Other management systems. 


\begin{tabular}{|c|c|c|c|c|c|c|c|c|c|c|c|c|c|c|c|}
\hline \multirow[t]{2}{*}{ 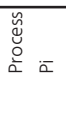 } & \multirow{2}{*}{$\begin{array}{l}\text { Estimation } \\
\text { of process } \\
\text { importance }\end{array}$} & \multicolumn{7}{|c|}{$\begin{array}{l}\text { Estimation of importance of sub process in the } \\
\text { frame of specific process }\end{array}$} & \multicolumn{7}{|c|}{ Estimation of importance of sub process goals } \\
\hline & & PP1 & PP2 & PP3 & PP4 & PP5 & PP6 & PP7 & PP1 & PP2 & PP3 & PP4 & PP5 & PP6 & PP7 \\
\hline P1 & 5 & 7 & 8 & 6 & & & & & 5 & 6 & 4 & & & & \\
\hline P2 & 6 & 6 & 7 & 7 & 8 & 7 & 6 & 5 & 5 & 6 & 7 & 6 & 6 & 7 & 6 \\
\hline P3 & 7 & 8 & 7 & 6 & 6 & & & & 6 & 6 & 7 & 8 & & & \\
\hline P4 & 7 & 6 & 7 & 6 & 7 & 6 & 7 & 8 & 7 & 7 & 8 & 7 & 7 & 7 & 8 \\
\hline P5 & 8 & 7 & 7 & 7 & 7 & & & & 7 & 7 & 7 & 7 & & & \\
\hline P6 & 8 & 7 & 6 & 7 & 6 & & & & 7 & 8 & 8 & 8 & & & \\
\hline P7 & 8 & 7 & 8 & 9 & 9 & 8 & & & 7 & 8 & 9 & 9 & 8 & & \\
\hline P8 & 8 & 5 & 6 & 6 & 6 & 5 & 5 & 6 & 7 & 7 & 7 & 7 & 7 & 6 & 8 \\
\hline
\end{tabular}

Table 9. Cross reference of processes, their importance and importance of their sub processes and goals

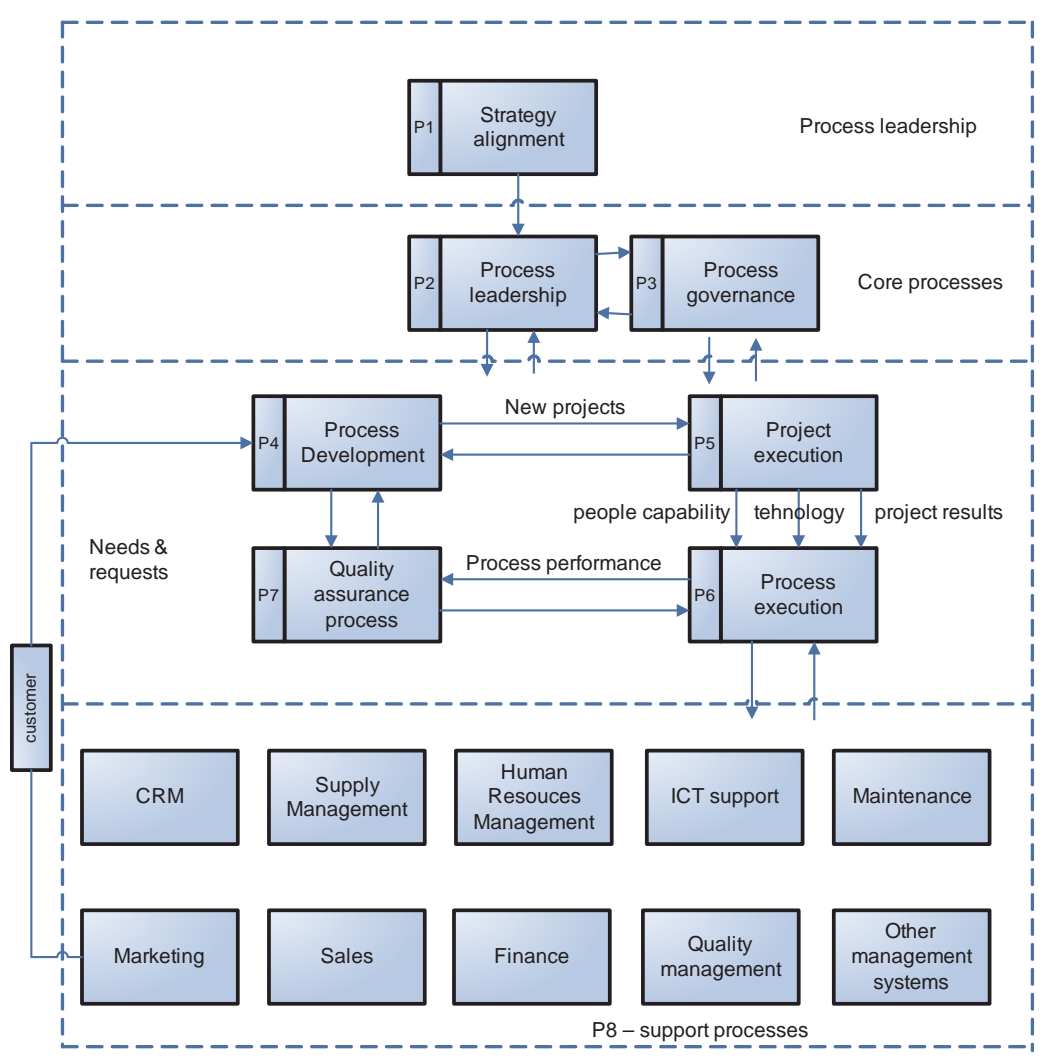

Figure 9. Process framework for companies in the food industry

Each process presented in figure 9 has its own importance as a whole. It is clear that each process could be decomposed on the accompanied sub processes. 


\begin{tabular}{|c|c|c|c|c|c|c|}
\hline \multicolumn{7}{|c|}{ Questionnaire } \\
\hline \multicolumn{3}{|c|}{ Questionnaire } & \multirow[t]{2}{*}{ M } & \multicolumn{3}{|c|}{ Questionnaire } \\
\hline \multirow[t]{4}{*}{1} & \multicolumn{2}{|c|}{ Questionnaire for strategy alignment } & & \multirow[t]{2}{*}{6} & \multicolumn{2}{|c|}{ Questionnaire for process execution } \\
\hline & 1 & $\begin{array}{l}\text { Estimation of strategic alignment of } \\
\text { processes; }\end{array}$ & & & 1 & Level of achieving of process goals \\
\hline & 2 & Estimation of strategic choices; & & & 2 & $\begin{array}{l}\text { Gap between planned and achieved } \\
\text { goals }\end{array}$ \\
\hline & 3 & Estimation of process architecture. & & & 3 & $\begin{array}{l}\text { Level of resource utilization (for process } \\
\text { needs): }\end{array}$ \\
\hline \multirow[t]{8}{*}{2} & \multicolumn{3}{|c|}{ Questionnaire for Process Leadership } & & 4 & Human; \\
\hline & 1 & Level of transformational leadership; & & & 5 & Equipment; \\
\hline & 2 & Level of transactional leadership; & & & 6 & ICT; \\
\hline & 3 & Level of trust in leadership; & & & 7 & Knowledge. \\
\hline & 4 & $\begin{array}{l}\text { Level of trust and communication in } \\
\text { organization; }\end{array}$ & & & 6.1 & Questionnaire for process performance \\
\hline & 5 & Level of business process awareness; & & & & $\begin{array}{l}\text { Evaluation of increase of process } \\
\text { awareness; }\end{array}$ \\
\hline & 6 & Level of process innovation; & & & & $\begin{array}{l}\text { Evaluation of definition and } \\
\text { establishment of rewards; }\end{array}$ \\
\hline & 7 & Level of promotion of manager success. & & & & $\begin{array}{l}\text { Evaluation of understanding or } \\
\text { responsibilities for the process; }\end{array}$ \\
\hline \multirow[t]{5}{*}{3} & \multicolumn{3}{|c|}{ Questionnaire for Process governance } & & & Evaluation of process metrics; \\
\hline & 1 & $\begin{array}{l}\text { Estimation of roles selection and } \\
\text { responsibilities; }\end{array}$ & & & & Evaluation of performance monitor; \\
\hline & 2 & Estimation of roles selection; & & & & $\begin{array}{l}\text { Evaluation of management of the } \\
\text { process; }\end{array}$ \\
\hline & 3 & $\begin{array}{l}\text { Estimation of evaluation and control of } \\
\text { management including estimation of } \\
\text { the risk of process; }\end{array}$ & & & & $\begin{array}{l}\text { Evaluation of continuous } \\
\text { improvement; }\end{array}$ \\
\hline & 4 & $\begin{array}{l}\text { Evaluation of implementation of } \\
\text { contemporary methods and tools in } \\
\text { business processes. }\end{array}$ & & & & Evaluation of communications. \\
\hline 4 & & tionnaire for Process development & & 7 & $\begin{array}{l}\text { Que } \\
\text { proc }\end{array}$ & $\begin{array}{l}\text { tionnaire for Quality assurance of } \\
\text { sses }\end{array}$ \\
\hline & 1 & $\begin{array}{l}\text { Evaluation of concept of desired } \\
\text { process; }\end{array}$ & & & 1 & $\begin{array}{l}\text { Level of effectiveness of processes - On } \\
\text { time Delivery of products }\end{array}$ \\
\hline
\end{tabular}




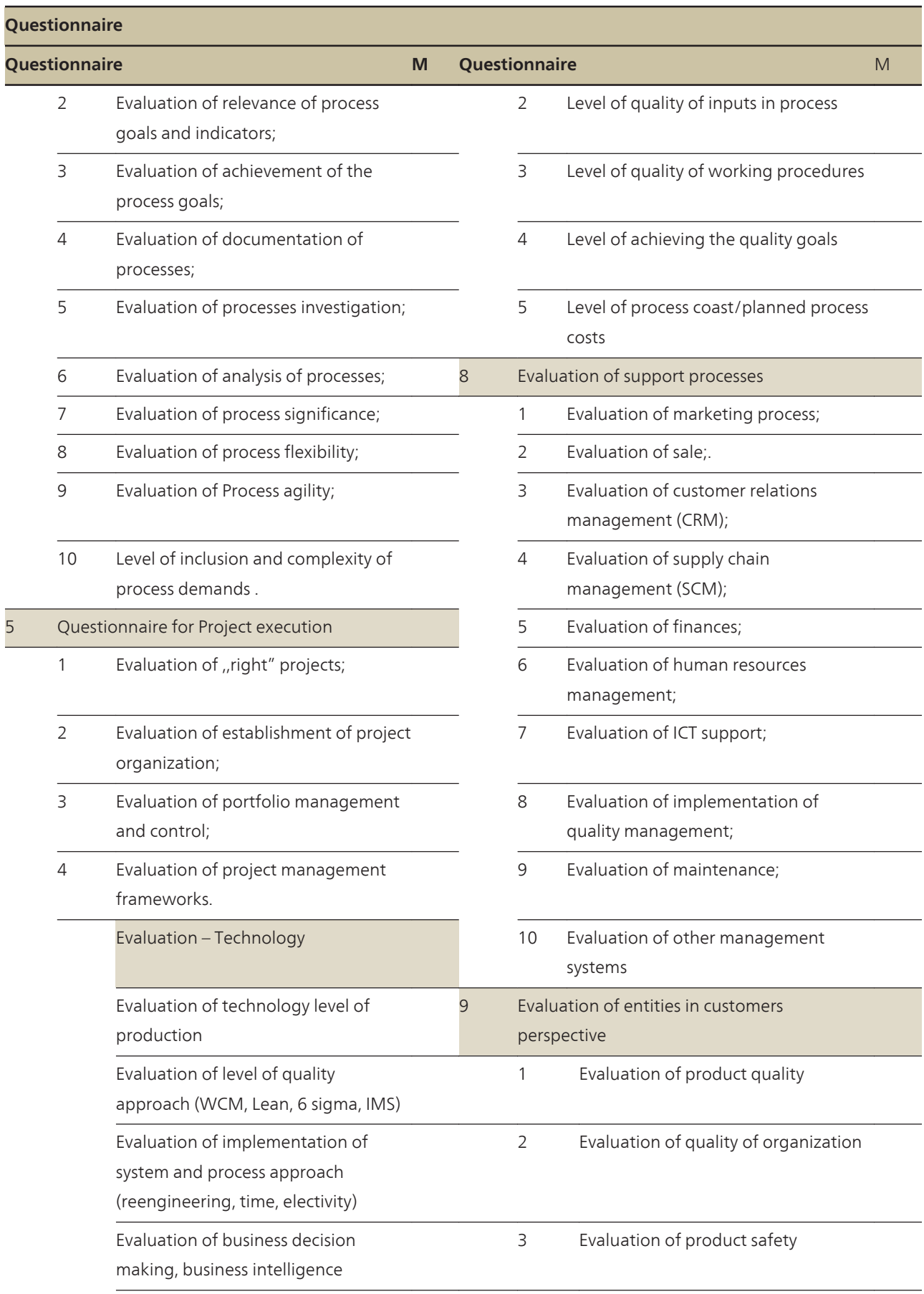




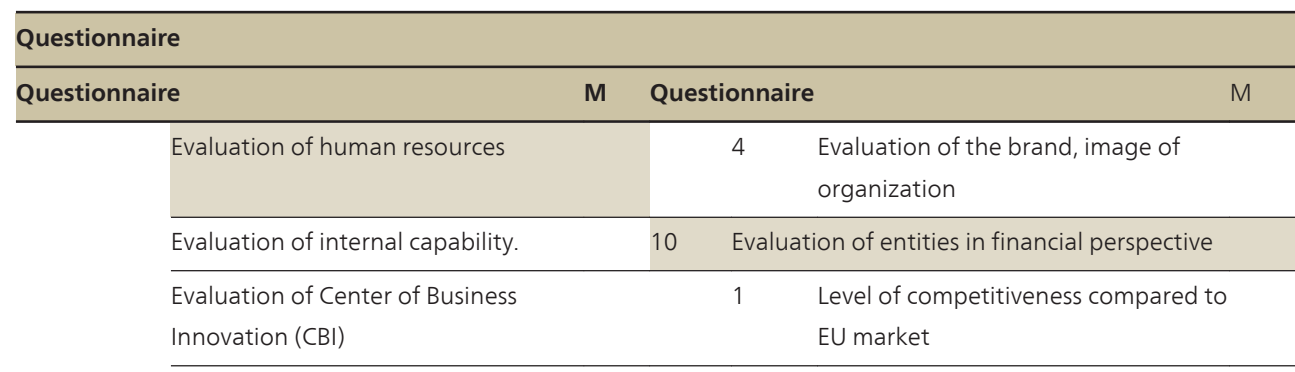

Evaluation of CBI engagement model.

Table 10. Questionnaire for Serbian companies

Total number of 53 companies were analyzed and results are presented in table 10.

Each sub process has importance in the frame of the specific process as well as the importance of its goal. The overall data gathered as the result of research in Serbian companies in the food industry is presented in table 9. The presented data could be combined with linguistically expressed opinion and used for ranking and simulation of quality goals according to the approach presented using fuzzy sets. Data were gathered using the questionnaire presented as table 10 .

\begin{tabular}{|c|c|c|c|c|c|c|c|c|c|c|c|c|c|c|c|}
\hline No. & Company & Stand. & 1 & 2 & 3 & 4 & 5 & 5.1 & 5.2 & 6 & 6.1 & 7 & 8 & 9 & 10 \\
\hline & Company 01 & 22000 & 8 & 6 & 7 & 7 & 5 & 8 & 8 & 1 & 7 & 9 & 8 & 6 & 9 \\
\hline & Company 02 & 22000 & 5 & 8 & 5 & 4 & 7 & 6 & 4 & 1 & 6 & 7 & 7 & 6 & 5 \\
\hline & Company 03 & 22000 & 7 & 6 & 7 & 5 & 8 & 6 & 4 & 1 & 7 & 5 & 9 & 7 & 2 \\
\hline & Company 04 & 22000 & 7 & 6 & 7 & 4 & 5 & 6 & 5 & 1 & 6 & 6 & 7 & 5 & 6 \\
\hline & Company 05 & 22000 & 6 & 8 & 5 & 5 & 7 & 8 & 7 & 1 & 7 & 6 & 9 & 8 & 6 \\
\hline & Company 06 & CAC & 4 & 7 & 2 & 2 & 5 & 5 & 1 & 1 & 5 & 2 & 6 & 4 & 3 \\
\hline & Company 07 & CAC & 5 & 7 & 4 & 4 & 6 & 8 & 4 & 1 & 6 & 5 & 8 & 8 & 3 \\
\hline & Company 08 & CAC & 7 & 8 & 6 & 4 & 6 & 8 & 5 & 1 & 8 & 7 & 9 & 7 & 5 \\
\hline & Company 09 & CAC & 3 & 6 & 2 & 2 & 6 & 4 & 1 & 1 & 3 & 2 & 4 & 4 & 2 \\
\hline & Company 10 & CAC & 5 & 6 & 5 & 3 & 5 & 4 & 4 & 1 & 4 & 4 & 6 & 4 & 5 \\
\hline & Company 11 & CAC & 6 & 7 & 6 & 5 & 5 & 6 & 6 & 1 & 5 & 7 & 7 & 5 & 8 \\
\hline & Company 12 & CAC & 4 & 7 & 4 & 3 & 5 & 6 & 2 & 1 & 5 & 5 & 5 & 5 & 4 \\
\hline & Company 13 & CAC & 4 & 5 & 4 & 2 & 5 & 6 & 5 & 1 & 5 & 4 & 6 & 6 & 4 \\
\hline & Company 14 & CAC & 4 & 5 & 3 & 3 & 7 & 5 & 4 & 1 & 6 & 6 & 6 & 6 & 2 \\
\hline & Company 15 & CAC & 5 & 6 & 5 & 3 & 6 & 8 & 1 & 1 & 5 & 5 & 6 & 7 & 4 \\
\hline & Company 16 & CAC & 4 & 4 & 3 & 3 & 4 & 4 & 3 & 1 & 5 & 4 & 4 & 3 & 4 \\
\hline
\end{tabular}




\begin{tabular}{|c|c|c|c|c|c|c|c|c|c|c|c|c|c|c|c|}
\hline No. & Company & Stand. & 1 & 2 & 3 & 4 & 5 & 5.1 & 5.2 & 6 & 6.1 & 7 & 8 & 9 & 10 \\
\hline & Company 17 & CAC & 4 & 3 & 2 & 2 & 4 & 3 & 1 & 1 & 4 & 1 & 3 & 3 & 3 \\
\hline & Company 18 & & 5 & 4 & 5 & 4 & 5 & 8 & 6 & 0 & 7 & 6 & 7 & 8 & 5 \\
\hline & Company 19 & & 5 & 3 & 5 & 3 & 5 & 8 & 6 & 1 & 7 & 6 & 7 & 8 & 2 \\
\hline & Company 20 & & 5 & 3 & 5 & 3 & 5 & 8 & 6 & 1 & 8 & 5 & 8 & 8 & 4 \\
\hline & Company 21 & & 4 & 2 & 4 & 3 & 4 & 9 & 7 & 0 & 6 & 5 & 6 & 7 & 7 \\
\hline & Company 22 & & 6 & 5 & 5 & 4 & 4 & 8 & 6 & 0 & 5 & 7 & 6 & 5 & 9 \\
\hline & Company 23 & & 4 & 3 & 4 & 2 & 6 & 7 & 5 & 0 & 5 & 4 & 5 & 5 & 3 \\
\hline & Company 24 & & 4 & 6 & 4 & 2 & 6 & 4 & 4 & 0 & 4 & 2 & 6 & 5 & 2 \\
\hline & Company 25 & & 4 & 4 & 4 & 2 & 6 & 4 & 4 & 0 & 5 & 2 & 7 & 7 & 2 \\
\hline & Company 26 & & 5 & 5 & 5 & 4 & 4 & 6 & 5 & 0 & 5 & 4 & 6 & 6 & 4 \\
\hline & Company 27 & & 5 & 5 & 5 & 4 & 6 & 7 & 5 & 0 & 6 & 6 & 5 & 5 & 6 \\
\hline & Company 28 & & 4 & 5 & 4 & 2 & 5 & 7 & 4 & 0 & 4 & 5 & 5 & 5 & 4 \\
\hline & Company 29 & & 4 & 2 & 4 & 3 & 5 & 5 & 4 & 0 & 5 & 4 & 6 & 7 & 5 \\
\hline & Company 30 & & 6 & 2 & 7 & 7 & 5 & 3 & 7 & 0 & 5 & 8 & 7 & 5 & 3 \\
\hline & Company 31 & & 4 & 5 & 4 & 3 & 4 & 5 & 5 & 0 & 4 & 4 & 5 & 5 & 3 \\
\hline & Company 32 & & 4 & 5 & 4 & 3 & 4 & 4 & 4 & 0 & 5 & 4 & 4 & 4 & 3 \\
\hline & Company 33 & & 5 & 5 & 4 & 3 & 4 & 5 & 4 & 0 & 4 & 5 & 6 & 6 & 4 \\
\hline & Company 34 & & 5 & 5 & 4 & 3 & 5 & 4 & 5 & 0 & 5 & 4 & 6 & 6 & 3 \\
\hline & Company 35 & & 4 & 5 & 4 & 3 & 4 & 4 & 4 & 0 & 5 & 4 & 5 & 5 & 3 \\
\hline & Company 36 & & 5 & 4 & 5 & 3 & 5 & 6 & 5 & 0 & 6 & 6 & 7 & 5 & 3 \\
\hline & Company 37 & & 4 & 4 & 3 & 2 & 4 & 4 & 5 & 0 & 6 & 5 & 6 & 5 & 3 \\
\hline & Company 38 & & 4 & 4 & 4 & 2 & 4 & 5 & 4 & 0 & 4 & 4 & 7 & 8 & 2 \\
\hline & Company 39 & & 5 & 5 & 5 & 2 & 5 & 3 & 4 & 0 & 4 & 4 & 5 & 6 & 4 \\
\hline & Company 40 & & 4 & 4 & 3 & 2 & 5 & 3 & 4 & 0 & 3 & 5 & 4 & 5 & 3 \\
\hline & Company 41 & & 4 & 4 & 2 & 1 & 6 & 5 & 4 & 0 & 5 & 4 & 5 & 5 & 3 \\
\hline & Company 42 & & 3 & 5 & 4 & 2 & 4 & 4 & 4 & 0 & 4 & 3 & 6 & 5 & 3 \\
\hline & Company 43 & & 4 & 4 & 4 & 2 & 4 & 5 & 4 & 0 & 6 & 4 & 6 & 5 & 4 \\
\hline & Company 44 & & 5 & 4 & 6 & 6 & 5 & 6 & 6 & 0 & 6 & 6 & 6 & 5 & 4 \\
\hline & Company 45 & & 2 & 6 & 1 & 1 & 2 & 2 & 1 & 0 & 2 & 1 & 4 & 6 & 2 \\
\hline & Company 46 & & 5 & 5 & 5 & 2 & 4 & 5 & 6 & 0 & 4 & 2 & 4 & 6 & 4 \\
\hline & Company 47 & & 3 & 5 & 3 & 2 & 3 & 6 & 2 & 0 & 3 & 2 & 5 & 6 & 3 \\
\hline & Company 48 & & 4 & 5 & 2 & 2 & 3 & 5 & 4 & 0 & 4 & 1 & 4 & 7 & 2 \\
\hline & Company 49 & & 8 & 4 & 6 & 7 & 4 & 4 & 3 & 0 & 3 & 6 & 7 & 6 & 8 \\
\hline
\end{tabular}




\begin{tabular}{|c|c|c|c|c|c|c|c|c|c|c|c|c|c|c|c|}
\hline No. & Company & Stand. & 1 & 2 & 3 & 4 & 5 & 5.1 & 5.2 & 6 & 6.1 & 7 & 8 & 9 & 10 \\
\hline & Company 50 & & 6 & 5 & 6 & 6 & 5 & 6 & 7 & 1 & 6 & 5 & 7 & 8 & 5 \\
\hline & Company 51 & & 5 & 7 & 7 & 7 & 7 & 7 & 7 & 1 & 7 & 6 & 7 & 7 & 4 \\
\hline & Company 52 & & 4 & 6 & 7 & 7 & 6 & 6 & 5 & 1 & 7 & 6 & 8 & 7 & 4 \\
\hline & Company 53 & & 6 & 4 & 6 & 6 & 5 & 7 & 3 & 0 & 5 & 5 & 8 & 8 & 7 \\
\hline
\end{tabular}

Legend: CAC - Codex Alimentarius - Food Hygiene, Recommended International Code of Practice General Principles of Food Hygiene CAC/RCP - 1969, Rev. 4-2003.

Table 11. Gathered data from Serbian companies

In table 11, the numbers in the columns correspond to the Questionnaire presented in table

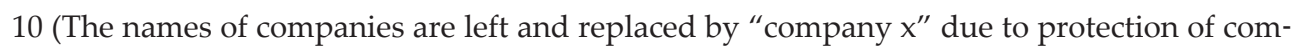
panies data.). Structure of the sample is: 25 organizations with less than 10 employees, 21 organizations with 10-50 employees, 3 organizations with 50-250 employees, 3 organizations with 250-500 employees and 1 organization with more than 500 employees.

Based on the expert opinion of consultants working with organizations in the sample the relation among processes and other entities are determined. The form of relation is: $R_{I, O}$ where I goal (performance) of entity and $\mathrm{O}$ - goal (performance source entity ) of destination entity

$$
\begin{array}{ll}
\text { RT, P4: } & \mathrm{GP} 4=\mathrm{GP} \text { ot }+0.11^{*} \Delta \mathrm{T} \\
\text { RT, P6: } & \mathrm{GP}=\mathrm{GP} \text { op }+0.15^{*} \Delta \mathrm{P} \\
\text { RP1, P: } & \mathrm{GP} 1=\mathrm{GP} 01+0.25^{*} \Delta \mathrm{P} \\
\text { RP2, P: } & \mathrm{GP}=\mathrm{GP} 02+0.28^{*} \Delta \mathrm{P} \\
\text { RP3, P: } & \mathrm{GP}=\mathrm{GP} 03+0.24^{*} \Delta \mathrm{P} \\
\text { RP4, P: } & \mathrm{GP} 4=\mathrm{GP} 04+0.27^{*} \Delta \mathrm{P} \\
\text { RP5, P: } & \mathrm{GP} 5=\mathrm{GP} 05+0.18^{*} \Delta \mathrm{P} \\
\text { RP6, P: } & \mathrm{GP}=\mathrm{GP} 06+0.16^{*} \Delta \mathrm{P} \\
\text { RP1, Q: } & \mathrm{GQ}=\mathrm{GQ} 01+0.30^{*} \Delta \mathrm{P} 1 \\
\text { RP2, Q: } & \mathrm{GQ}=\mathrm{GQ} 02+0.32^{*} \Delta \mathrm{P} 2 \\
\text { RP3, Q: } & \mathrm{GQ}=\mathrm{GQ} 03+0.29^{*} \Delta \mathrm{P} 3 \\
\text { RP4, Q: } & \mathrm{GQ}=\mathrm{GQ} 04+0.35^{*} \Delta \mathrm{P} 4 \\
\text { RP5, Q: } & \mathrm{GQ}=\mathrm{GQ} 05+0.18^{*} \Delta \mathrm{P} 5 \\
\text { RP6, Q: } & \mathrm{GQ}=\mathrm{GQ} 06+0.17^{*} \Delta \mathrm{P} 6 \\
\text { RP7, Q: } & \mathrm{GQ}=\mathrm{GQ} 07+0.24^{*} \Delta \mathrm{P} 7 \\
\text { RP8, Q: } & \mathrm{GQ}=\mathrm{GQ} 08+0.17^{*} \Delta \mathrm{P} 8
\end{array}
$$
$\mathrm{RP} 1, \mathrm{~S}: \mathrm{GS}=\mathrm{GS} 01+0.03^{*} \Delta \mathrm{P} 1$
$\mathrm{RP} 2, \mathrm{~S}: \mathrm{GS}=\mathrm{GSO} 2+0.04^{*} \Delta \mathrm{P} 2$
RP3, S: GS $=\mathrm{GSO3}+0.08^{*} \Delta \mathrm{P} 3$
$\mathrm{RP} 4, \mathrm{~S}: \mathrm{GS}=\mathrm{GS} 04+0.18^{*} \Delta \mathrm{P} 4$
RP6, S: GS $=\mathrm{GS06}+0.28^{*} \Delta \mathrm{P} 6$
RP7, S: GS $=\mathrm{GS} 07+0.15^{*} \Delta \mathrm{P} 7$
RP8, S: GS $=\mathrm{GS} 08+0.20^{*} \Delta \mathrm{P} 8$
R S, I: $\quad \mathrm{GI}=\mathrm{GSO}+0.38^{*} \Delta \mathrm{I}$
RP6, I: $\quad \mathrm{GI}=\mathrm{GI06}+0.32 * \Delta \mathrm{P} 6$
RP7, I: $\quad \mathrm{GI}=\mathrm{GI} 07+0.30^{*} \Delta \mathrm{P} 7$
RP8, I: $\quad \mathrm{GI}=\mathrm{GI0} 8+0.35^{*} \Delta \mathrm{P} 8$
$\mathrm{RQ}, \mathrm{C}: \quad \mathrm{GC}=\mathrm{GQ} 0+0.39 * \Delta \mathrm{Q}$
$\mathrm{RS}, \mathrm{C}: \mathrm{GC}=\mathrm{GSO}+0.28^{*} \Delta \mathrm{S}$
RI, C : GC $=\mathrm{GIO}+0.15^{*} \Delta \mathrm{I}$ 
Starting values of constants are determined by investigation of the organization in the sample. Presented relations describe the importance of relations presented in the strategy map.

\section{Conclusion}

The food industry is a sector that is involved in rapid, multidimensional changes. At the same time this is an industrial sector that is emerging and increasing its importance in relation to different trends and challenges: growth of population, increased need for healthy food, food safety regulations, and different customers' demands.

It is completely clear that the food industry must respond in many different directions in order to avoid challenges, reduce threats and explore its strengths using available opportunities. Some of the changes in the food industry will go in the direction of automation of the production process and technological changes, employing the full potential of biotechnology, information and communication technology, RFID, robotics, sensors and even e-business. Other changes will be directed in the optimization of logistic infrastructure and energy savings. But companies in the food industry will also need to understand globalization trends, market developments and chanciness and swings in customers' needs. All these changes will increase the success of the food industry on the global markets. Although all of these changes could have only limited, partial results that will not fulfill the complete potential of the suggested changes if companies do not restructure their organizations and redesign their processes. Changing and adopting the changes of organization as well as restructure and redesign of processes are a pre-condition for all other changes. On the other hand, companies usually do not pay much attention to organizational challenges and process redesign, compared with other directions of changes such as the implementation of new and emerging technologies.

In this chapter we addressed different questions and issues in the redesign of process development in food production organizations using quality engineering tools and methods. The first step is analysis of existing processes, its decomposition and introduction of quality metrics for evaluation of the quality of processes and quality of goals. A typical process map for a company in the food processing industry in Serbia is presented and the production process is decomposed on sub processes. All indicators for quality metrics were proposed as numeric values in order to clearly demonstrate the concept.

After decomposition another step is redesign of process development. Different changing methodologies are compared according to the amount of change, score of change, used tools, probability of success and their applicability in food industry. The concept of continuous process improvement is presented and redesign of the process has 5 phases with 10 steps. Different quality engineering methods and tools used in the food industry were compared according to the frequency of their usage and correlation to increase of profit in Serbian companies. The general conclusion was that companies are using older, established methods and tools even if they do not have that large impact on profit increase compared to the modern tools and methods. A total number of 20 different quality engineering methods 
and tools were analyzed among 53 Serbian companies from the food industry sector. With many different problems, starting from the ranking of importance of quality goals, ranking of importance of processes or entities, up to ranking the methods or tools, there is a need for an approach that will solve these issues. All these problems could be solved by usage of the fuzzy approach. As an extension of the general ranking idea presented on the ranking and definition of goals in the production process, the fuzzy approach for evaluation of the importance of entities in supply chains in the food industry is presented. A strategic map as a strategic part of the BSC (Balanced Score Card) framework is presented as the role model for food processing companies. The special contributions of this map are the relations between entities (from all four perspectives) that are defined as the result of the research in Serbian companies. In addition, the framework of processes for the companies from the food industry was presented. Finally, the general contribution of all the presented issues, decomposition, redesign, evaluation of quality tools and methods, fuzzy ranking and the strategic map, is based on results of research in 53 Serbian companies. The questionnaire for Serbian companies is presented as well as the results of research. A very important contribution presented is the fact that all decompositions, redesigns, modeling, simulations and calculations were performed using real life data acquired from Serbian companies.

A possible and very useful extension of this research would be a comparison of data with data from the EU but according to the literature the variation would not be significant.

\section{Acknowledgements}

The research presented in this paper was supported by The Ministry of Science and Technological Development of The Republic of Serbia, Grant III-44010, Title: Intelligent Systems for Software Product Development and Business Support based on Models.

\section{Author details}

Slavko Arsovski, Miladin Stefanović, Danijela Tadić and Ivan Savović

*Address all correspondence to: miladin@kg.ac.rs

Center for Quality, Faculty of Engineering, University of Kragujevac, Serbia

\section{References}

[1] Trends and drivers of change in the food and beverage industry in Europe: Mapping report, www.eurofound.eu.int 
[2] Nikhil Daxini, Use BPM to Assist in New Product Development, TRIZ Journal, http:// www.triz-journal.com/content/c081201a.asp

[3] Aikens, H., Quality Inspired Management: The Key to Sustainability, Prentice Hall, 2011.

[4] Hur, M., The influence of total quality management practices on the transformation of how organizations works, Total Management and Business Intelligence, Vol. 20, Numbers 7-8, p. 847 - 863, ISSN: 1478 - 3363, 2009.

[5] Foster, T., Managing Quality: Integrating the supply chain, Prentice Hall, ISBN: 978-0-13-507819-8, 2010.

[6] Summers, D., Quality Management: Creating and Sustaining Organizational Effectiveness, Pearson International Edition, 2009.

[7] Foster, T., Managing Quality: An Integrative Approach, Pearson \& Prentice Hall, 2004, ISBN: 0-13-123018-3

[8] Juran, J., Managerial Breakthrough, Mc Grow Hill, New York, 1995.

[9] Rao et all., Total Quality Management: A Cross Functional Perspective, John Willey \& Sons, New York, 1996.

[10] Goetch, D., Davis, S., Introduction to Total Quality, Prentice Hall, Upper Saddle River, New Jersey, 1997.

[11] Jeston, J., Nelis, J., Business Process Management, Elsevier, Amsterdam, 2008.

[12] Born, G., Process Management to Quality Improvement, John Willey \& Sons, New York, 1996.

[13] Davenport T.H., Process Innovation Reengineering Work Through Information Technology, Boston, MA, 1993.

[14] Zimmermann, H.J., Fuzzy set Theory and its applications. Kluwer Nijhoff Publising: Boston, 1996.

[15] Klir, G.J., Folger, T.A., Fuzzy Sets, Uncertainty and Information, Pretence-Hall, Englewood, Cliffs, NJ., 1988.

[16] Chang, D.Y., Applications of the extent analysis method on fuzzy AHP, European Journal of Operational Research, 95, 649-655, 1996.

[17] Tadić, D., Milanović, D., Misita, M., Tadić, B., New integrated approach to the problem of ranking and supplier selection under uncertainties, Proceedings of the Institution of Mechanical Engineers. Part B: Journal of Engineering manufacture, doi: 10.1243/09544054JEM2105.

[18] Saaty, T.L., How to make a decision: The Analytic Hierarchy Process, European Journal of Operational Research, 48, 9-26, 1990. 
[19] Shih, H.S., Shyur, H.J., Lee, E.S., 2007. An extension of TOPSIS for group decision making. Mathematical and Computer Modelling 45 (7/8), 801-813.

[20] Marić, A, Arsovski, S., Mastilović, J.: Contribution to the improvement of products quality in baking industry, International Journal for Quality research, Vol.3, No. 3, pp. 209-216, 2009

[21] D. Tadić, M. Stefanović, D. Milanović, Fuzzy Approach in Evaluation of Operations in Food Production, International Journal for Quality Research, Vol1, no 2, pp 97 104, 2007. 